\title{
The Glycine Transporter GlyT2 Controls the Dynamics of Synaptic Vesicle Refilling in Inhibitory Spinal Cord Neurons
}

\author{
France Rousseau, ${ }^{1,2}$ Karin R. Aubrey, ${ }^{1,2}$ and Stéphane Supplisson ${ }^{1,2}$ \\ ${ }^{1}$ Laboratoire de Neurobiologie, Ecole Normale Supérieure, 75005 Paris, France, and ${ }^{2}$ Centre National de la Recherche Scientifique, 75005 Paris, France
}

\begin{abstract}
At inhibitory synapses, glycine and GABA are accumulated into synaptic vesicles by the same vesicular transporter VGAT/VIAAT (vesicular GABA transporter/vesicular inhibitory amino acid transporter), enabling a continuum of glycine, GABA, and mixed phenotypes. Many fundamental aspects of the presynaptic contribution to the inhibitory phenotypes remain unclear. The neuronal transporter GlyT2 is one of the critical presynaptic factors, because glycinergic transmission is impaired in knock-out $\mathrm{GlyT}^{-/-}$mice and mutations in the human GlyT2 gene slc6a5 are sufficient to cause hyperekplexia. Here, we establish that GlyT2-mediated uptake is directly coupled to the accumulation of glycine into recycling synaptic vesicles using cultured spinal cord neurons derived from GlyT2- enhanced green fluorescent protein transgenic mice. Membrane expression of GlyT2 was confirmed by recording glycine-evoked transporter current. We show that GlyT2 inhibition induces a switch from a predominantly glycine to a predominantly GABA phenotype. This effect was mediated by a reduction of glycinergic quantal size after cytosolic depletion of glycine and was entirely reversed by glycine resupply, illustrating that the filling of empty synaptic vesicles is tightly coupled to GlyT2-mediated uptake. Interestingly, high-frequency trains of stimuli elicit two phases of vesicle release with distinct kinetic requirements for glycine refilling. Thus, our results demonstrate the central role played by GlyT2 in determining inhibitory phenotype and therefore in the physiology and pathology of inhibitory circuits.
\end{abstract}

Key words: inhibitory transmission; glycine transporter; vesicular transporter; quantal size; spinal cord; paired recordings

\section{Introduction}

New and recycled synaptic vesicles are filled with a high concentration of neurotransmitter by specific vesicular $\mathrm{H}^{+}$antiporters (Sulzer and Pothos, 2000; Edwards, 2007), yet despite the importance of this loading step for the completeness of vesicle recycling, little is known about its dynamics and the thermodynamic, kinetic, and osmotic constraints that regulate the vesicular storage of neurotransmitters under physiological conditions (Sulzer and Pothos, 2000; Liu, 2003; Edwards, 2007). In particular, it is not known how glycinergic, GABAergic, and mixed GABAergic/glycinergic vesicular phenotypes are specified at individual synapses in inhibitory neurons (Jonas et al., 1998), in which vesicular inhibitory amino acid transporter (VIAAT) (also named VGAT, for vesicular GABA transporter) is the unique vesicular transporter for the two inhibitory amino acids neurotransmitters (Burger et al., 1991; McIntire et al., 1997; Sagné et al., 1997; Wojcik et al., 2006; Aubrey et al., 2007). Although the proportions of glycine

\footnotetext{
Received Feb. 4, 2008; revised Aug. 1, 2008; accepted Aug. 9, 2008.

This work was supported by Centre National de la Recherche Scientifique, Inserm (S.S.), and grants from the Action Concertée Incitative "Biologie du Développement et Physiologie Intégrative" from the Ministère de la Recherche et de la Technologie (MRT), the Fédération pour la Recherche sur le Cerveau, and the Association Française contre les Myopathies (AFM). F.R. was a recipient of MRT and AFM PhD fellowships. K.R.A. was supported by European Marie-Curie and Fondation pour la Recherche Médicale fellowships. We thank Philippe Ascher, Païkan Marcaggi, and Boris Barbour for critical reading and suggestions on this manuscript. We thank Stéphane Dieudonné for discussion, and Hanns U. Zeilhofer for providing the GlyT2-EGFP mice.

Correspondence should be addressed to Stéphane Supplisson, Laboratoire de Neurobiologie, Ecole Normale Supérieure, Centre National de la Recherche Scientifique, 46 rue d'Ulm, 75005 Paris, France. E-mail: stephane.supplisson@biologie.ens.fr.

D0I:10.1523/JNEUROSCI.0509-08.2008

Copyright $\odot 2008$ Society for Neuroscience $\quad 0270-6474 / 08 / 289755-14 \$ 15.00 / 0$
}

and GABA in vesicles are expected to be determined by the relative concentrations of the neurotransmitters in the cytoplasm, vesicles released by isolated terminals (Katsurabayashi et al., 2004) or by VIAAT-transfected cells (Aubrey et al., 2007) evoked heterogeneous patterns of transmission, suggesting heterogeneous vesicular loading.

Although glycine is an ubiquitous intracellular metabolite, its basal synthesis cannot account for the 10- to 100-fold larger accumulation detected in glycinergic neurons (Daly, 1990; Ottersen et al., 1990). Thus, local recapture is considered to be the main mechanism of glycine supply at the terminals. Glycinergic neurons in the spinal cord and the brainstem express GlyT2, a transporter of the SLC6 family (Liu et al., 1993; Jursky and Nelson, 1995; Zafra et al., 1995) that mediates unidirectional transport of glycine coupled to $3 \mathrm{Na}^{+} / 1 \mathrm{Cl}^{-}$(Roux and Supplisson, 2000). In a model system of inhibitory transmission, it has been shown that the only requirement for glycine accumulation into vesicles is the coexpression of GlyT2 and VIAAT (Aubrey et al., 2007). In addition, glycinergic transmission is impaired in brainstem slices of GlyT2 ${ }^{-1-}$ knock-out mice (Gomeza et al., 2003) and sporadic mutations in human slc6a5, the gene that encodes GlyT2 that abolishes glycine uptake, cause hyperekplexia (Rees et al., 2006), a neuromuscular startle syndrome attributed principally to mutations in the $\alpha 1$ subunit of the glycine receptor (GlyR) (Shiang et al., 1993).

Here, we investigate the relationship between GlyT2mediated glycine uptake and vesicle filling in pairs of spinal cord neurons in culture. A GlyT2-enhanced green fluorescent protein (EGFP) transgenic mouse line enabled identification of GlyT2positive $\left(\mathrm{GlyT}_{2}{ }^{+}\right)$neurons (Zeilhofer et al., 2005), and the cul- 
ture preparation allowed us to control intracellular and extracellular glycine. We show that uptake by GlyT2 drives the filling of synaptic vesicles with glycine and regulates quantal size in inhibitory neurons. Interestingly, we found that blocking GlyT2 induces a switch from predominantly glycinergic to predominantly GABAergic phenotypes. In addition, we highlight kinetic constraints in the supply of glycine for vesicle refilling during highfrequency release.

\section{Materials and Methods}

Embryonic mouse spinal cord neurons. Primary cultures of spinal cord neurons were prepared as described by Hanus et al. (2004) from embryonic day 13 or 14 C57BL/6 wild-type (WT) or heterozygous GlyT2-EGFP mouse pups (Zeilhofer et al., 2005). Embryos were obtained by cesarean section from pregnant mice anesthetized by intraperitoneal injection of ketamine-xylazine (100 and $10 \mathrm{mg} / \mathrm{kg}$ ) and killed by cervical elongation. Spinal cords were dissected under sterile conditions into PBS with $33 \mathrm{~mm}$ glucose at pH 7.4 and then incubated in trypsin/EDTA solution $(0.05 \%$ $\mathrm{v} / \mathrm{v}$; Sigma) for $10 \mathrm{~min}$ at $37^{\circ} \mathrm{C}$. Cells were dissociated mechanically in a modified L15 Leibowitz's medium (Invitrogen) and plated at a density of $0.4 \times 10^{5}$ cells $/ \mathrm{cm}^{2}$ on sterilized glass coverslips coated with $60 \mu \mathrm{g} / \mathrm{ml}$ poly-DL-ornithine and with medium containing $5 \%$ inactivated fetal calf serum (Sigma). Cells were maintained at $37^{\circ} \mathrm{C}$ in $5 \% \mathrm{CO}_{2}$ in serum-free Neurobasal medium containing supplement B27 (Invitrogen) (Brewer et al., 1993) for up to 3 weeks. Medium was changed every $4-5 \mathrm{~d}$.

Electrophysiology: procedures and solutions. Whole-cell patch-clamp recordings of spinal cord neurons [12-22 d in vitro (DIV)] were performed at $\sim 30^{\circ} \mathrm{C}$. Voltage-clamp and current-clamp modes were applied using a Multiclamp 700B or two Axopatch 200A amplifiers controlled by pClamp 9 or 10 acquisition software (Molecular Devices). Currents were filtered at $4 \mathrm{kHz}$ and sampled at $20 \mathrm{kHz}$ using a Digidata 1440A or 1322A (Molecular Devices). Patch pipettes were pulled from borosilicate glass capillaries (Hilgenberg) and had resistances of 4-6 $\mathrm{M} \Omega$. Miniature and evoked currents were recorded at a holding potential $\left(V_{\mathrm{H}}\right)$ of $-60 \mathrm{mV}$ using pipettes filled with a standard internal solution containing the following (in mM): $140 \mathrm{CsCl}, 1 \mathrm{CaCl}_{2}, 10 \mathrm{EGTA}, 1 \mathrm{BAPTA}$, $1 \mathrm{MgCl}_{2}, 4 \mathrm{Mg}$-ATP, 5 QX314 [N-(2,6-dimethylphenylcarbamoylmethyl)triethylammonium-Cl], and 10 HEPES, adjusted to $\mathrm{pH} 7.4$ with $\mathrm{CsOH}$. For paired recordings, the internal solution for the presynaptic neurons contained the following (in $\mathrm{mM}$ ): $155 \mathrm{~K}$-gluconate, $4 \mathrm{KCl}, 5$ Mg-ATP, 0.1 EGTA, and 10 HEPES, adjusted to $\mathrm{pH} 7.4$ with KOH. To record GlyT2-mediated currents, the internal solution was the following (in $\mathrm{mM}$ ): $130 \mathrm{CsCH}_{3} \mathrm{O}_{3} \mathrm{~S}, 1 \mathrm{CaCl}_{2}, 10$ EGTA, 1 BAPTA, $5 \mathrm{Mg}$-ATP, 5 tetraethylammonium- $\mathrm{Cl}, 5 \mathrm{QX} 314-\mathrm{Cl}$, and 10 HEPES, adjusted to $\mathrm{pH}$ 7.4 with $\mathrm{CsOH}$. Neurons were continuously bathed with an external solution containing the following (mM): $140 \mathrm{NaCl}, 2.4 \mathrm{KCl}, 4 \mathrm{CaCl}_{2}, 1$ $\mathrm{MgCl}_{2}, 10$ glucose, and 10 HEPES, $\mathrm{pH}$ 7.4. AMPA and NMDA receptors were blocked with $2 \mu \mathrm{M}$ 6-nitro-7-sulfamoylbenzo[f] quinoxaline-2,3dione (NBQX) and $50 \mu \mathrm{M} \mathrm{D}-( \pm)$-2-amino-5-phosphonovaleric acid (D$\mathrm{APV})$, respectively. $\mathrm{GABA}_{\mathrm{A}}$ receptors $\left(\mathrm{GABA}_{\mathrm{A}} \mathrm{Rs}\right)$ were selectively blocked with $5 \mu \mathrm{M}$ gabazine (SR95531 [2-(3-carboxypropyl)-3-amino6-(4-methoxyphenyl)pyridazinium bromide]). $\mathrm{GABA}_{\mathrm{B}}$ receptors $\left(\mathrm{GABA}_{\mathrm{B}} \mathrm{Rs}\right)$ were blocked with CGP55845 [(2S)-3([(1S)-1(3,4-dichlorophenyl)ethyl] amino-2-hydroxypropyl)(phenylmethyl)phosphonic acid]. GlyRs were blocked with $3 \mu \mathrm{M}$ strychnine, and larger concentrations $(10-30 \mu \mathrm{M})$ were used when glycine was present in the external solution. GlyT2 was inhibited with $5 \mu \mathrm{M}$ ORG25543 (4-benzyloxy-3,5dimethoxy- $N$-[(1-dimethylaminocyclopentyl)methyl]benzamide) (generous gift from H. Sundaram and D. Hill, Organon, Newhouse, UK); other drugs were purchased from Sigma or Tocris Cookson.

Miniature events were recorded in the presence of $0.2 \mu \mathrm{M}$ tetrodotoxin (TTX) from neurons isolated from WT or GlyT2-EGFP embryos between 16 and 22 DIV.

For paired recordings, presynaptic GlyT2 ${ }^{+}$neurons and putative postsynaptic neurons $\left[\mathrm{GlyT}^{+}\right.$or GlyT2-negative $\left(\mathrm{GlyT}^{-}\right)$] were patched and tested for synaptic connection. Action potentials (APs) were triggered under current clamp by $10 \mathrm{~ms}$ depolarizing current steps com- prised between 140 and $360 \mathrm{pA}$ at $0.1-5 \mathrm{~Hz}$. Evoked IPSCs were recorded in the presence of $50 \mu \mathrm{M}$ D-APV and $2 \mu \mathrm{M}$ NBQX.

GlyT2-mediated currents were recorded from neurons expressing EGFP, between 18 and 22 DIV. Neurons were held at $V_{\mathrm{H}}$ of $-80 \mathrm{mV}$ and bathed with standard external solution containing TTX $(0.2 \mu \mathrm{M})$ and cadmium chloride $(20 \mu \mathrm{M})$. Current-voltage $(I-V)$ relationships were isolated by subtraction of glycine $(200 \mu \mathrm{M})$ stimulated steady-state currents from those recorded in the external solution alone. Currents were normalized to the absolute value recorded at $V_{\mathrm{H}}$ of $-50 \mathrm{mV}$.

Data analysis. Miniature synaptic currents were detected using the Clampfit template procedure. Recordings with less than five glycinergic miniature IPSCs (mIPSCs) were discarded from the amplitude analysis. To take into account combined changes in amplitude and frequency, the sum of mIPSC amplitudes per minute was calculated for each cell.

The latency for paired recordings was measured as the delay between the peak of the action potential and the maximum of the rising slope of the postsynaptic current. Evoked IPSC decays were fitted by one exponential or by the sum of two exponentials $I(t)=A_{1} \exp \left(-t / \tau_{1}\right)+A_{2}$ $\exp \left(-t / \tau_{2}\right)$, where $A_{1}$ and $A_{2}$ are the amplitudes of the components (with identical sign), and $\tau_{1}$ and $\tau_{2}$ are the time constants. The amplitudeweighted decay time constant was calculated as $\tau_{w}=\left(A_{1} \tau_{1}+A_{2} \tau_{2}\right) /\left(A_{1}\right.$ $\left.+A_{2}\right) \cdot \mathrm{CV}^{2}$ analysis was used to predict the locus of synaptic depression (Faber and Korn, 1991). For each train of 1000 APs, mean amplitude $(\mu)$, $\mathrm{SD}(\sigma)$, and coefficient of variation $(\mathrm{CV}=\sigma / \mu)$ of 40 IPSCs were computed at the onset (APs 2 and $\left.41 ; \mathrm{CV}_{1}, \mu_{1}\right)$ and at the end $\left(\mathrm{CV}_{2}, \mu_{2}\right)$ of the stimulation. Then, $\frac{C V_{1}^{2}}{C V_{2}^{2}}$ was plotted as a function of $\frac{\mu_{2}}{\mu_{1}}$ as described by Faber and Korn (1991).

Responses evoked by $5 \mathrm{~Hz}$ stimulation were normalized by the first IPSC amplitude or by the average amplitude between APs 3 and 32. In semilogarithmic plots, IPSC amplitudes between the APs 4 and 1000 were averaged using a constant logarithmic bin of 0.1 .

Electrophysiological results are reported as mean \pm SEM. All statistical tests were nonparametric. The Mann-Whitney $U$ test and the sign test were used to assess differences between two independent and two related samples, respectively. The Kolmogorov-Smirnov test was used to assess the equality of the two distributions. For all tests, the number of asterisks in the figures corresponds to level of significance: ${ }^{\star} p<0.05,{ }^{* *} p<0.01$, and ${ }^{* * *} p<0.001$.

FM 4-64 imaging. GlyT2-EGFP spinal cord neurons were incubated for $3 \mathrm{~min}$ at $37^{\circ} \mathrm{C}$ in a depolarizing extracellular solution containing the following: $102.4 \mathrm{~mm} \mathrm{NaCl}, 40 \mathrm{~mm} \mathrm{KCl}, 1 \mathrm{~mm} \mathrm{MgCl}, 2 \mathrm{~mm} \mathrm{CaCl}_{2}, 10 \mathrm{~mm}$ glucose, $10 \mathrm{~mm}$ HEPES, pH 7.3, and $10 \mu \mathrm{M}$ FM 4-64 [ $N$-(3-triethylammoniumpropyl)-4-(6-(4-diethylamino)phenyl)hexatrienyl)pyridinium dibromide] (Invitrogen). Coverslips were washed for 20 min twice with the external solution containing TTX $(0.5 \mu \mathrm{M})$ in the presence $(1 \mathrm{mM})$ or absence of ADVASEP-7 [sulfonated $\beta$-cyclodextrin (Sigma)] (Kay et al., 1999). FM 4-64-labeled puncta were destained at $30^{\circ} \mathrm{C}$ by electrical stimulation as reported by Jungling et al. (2006) using large-diameter pipettes filled with standard extracellular solution attached to an Axoporator 800A (Molecular Devices). One-second bursts of square pulses $(-60 \mathrm{~V}, 2$ $\mathrm{ms}$ in duration) were applied at $10 \mathrm{~Hz}$. Fluorescence images $(11007 \mathrm{v} 2$ filter; Chroma Technology) were acquired at $0.2 \mathrm{~Hz}$ using a Coolsnap-ES CCD camera (Roper Scientific) and a LUCPLFL $40 \times / 0.6$ relief contrast objective (Olympus) with MetaView 5 software (Universal Imaging). Illumination $(200 \mathrm{~ms})$ was controlled with an electronic shutter (Uniblitz shutters; Vincent Associates). For time-lapse recordings, the average fluorescence intensities of individual boutons were normalized after background subtraction to the initial fluorescence intensity recorded before stimulation. Only boutons with colocalized FM 4-64 and EGFP fluorescence were analyzed. Final images were processed using Adobe Photoshop 9.0 software (Adobe Systems).

Glycine iontophoresis. Iontophoresis pipettes were pulled from thinwalled glass (WPI) to have a resistance of 150-200 $\mathrm{M} \Omega$ when filled with $15 \mathrm{~mm}$ glycine, $\mathrm{pH}$ 2. The iontophoresis pipette was then moved close to neurites originating from the patch-clamped neuron. Fast glycine responses were elicited using a stimulator (A-M Systems 2100) with positive voltage steps of $1 \mathrm{~ms}$ in the range of $5-25 \mathrm{~V}$ and a small holding voltage $(-0.1$ to $-1 \mathrm{~V})$. The iontophoresis pipette position and holding 
A
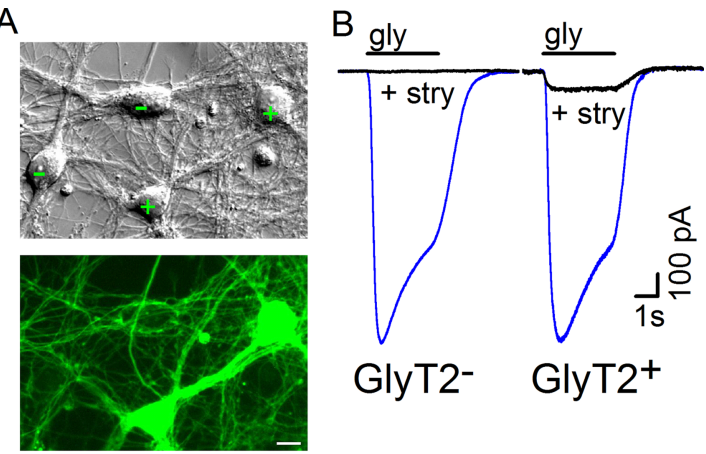

C $_{\text {stry }}$

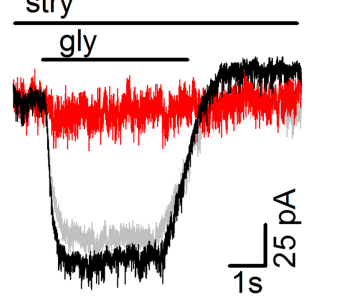

GlyT2 $^{+}$

- gly+ORG25543

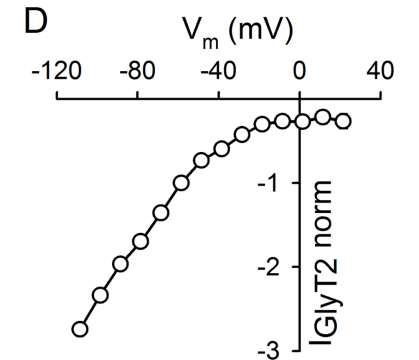

Figure 1. GlyT2-mediated currents in cultured spinal cord neurons. $A$, GlyT2 positive $(+)$ or negative (-) neurons isolated from GlyT2-EGFP mice (top) were identified by their green fluorescence (bottom). Scale bar, $10 \mu \mathrm{m}$. B, Traces of currents evoked by glycine (200 $\mu \mathrm{m})$ in GlyT2 ${ }^{-}$neurons (left trace) and GlyT2 ${ }^{+}$neurons (right trace) in the absence (blue line) or presence (20 $\mu \mathrm{m}$; solid line) of strychnine (stry). C, The strychnine-insensitive glycine-evoked current of GlyT2 ${ }^{+}$neurons (solid line) was inhibited by 0RG25543 (5 $\mu \mathrm{m}$; red line), reversibly (gray line; 40 min wash). D, $I-V$ relationship of the GlyT2-mediated current (I-V values were normalized by their absolute values at $V_{\mathrm{m}}$ of $-50 \mathrm{mV} ; n=10$ ).

voltage were not changed once it was optimally adjusted, and the amount of glycine release was modulated by changing the intensity of the positive voltage step. SR95531 (70 and $500 \mu \mathrm{M})$ was bath applied. Control solutions all contained $5 \mu \mathrm{M}$ SR95531 (see above, Electrophysiology: procedures and solutions). The current traces presented in Figure $6 \mathrm{~A}$ are the average from 20-30 consecutive iontophoretic pulses. The coefficients of variation were $0.197,0.074$, and 0.026 at 10,15 , and $20 \mathrm{~V}$ stimulation, respectively.

\section{Results}

We set out to study the role of GlyT2 for the refilling of synaptic vesicles with glycine, in pairs of cultured spinal neurons with identified presynaptic GlyT2 neurons, using transgenic GlyT2EGFP mice (Zeilhofer et al., 2005).

\section{GlyT2 transporter currents}

To confirm the functional expression of GlyT2 in green fluorescent neurons, we examined the glycine-evoked current recorded from $\mathrm{GlyT}_{2}{ }^{+}$or GlyT2 ${ }^{-}$neurons (Fig. $\left.1 A\right)\left(50 \pm 1.7 \%\right.$ GlyT2 $^{+}$ neurons/coverslip; $n=127)$. In all neurons tested, fast application of glycine $(200 \mu \mathrm{M})$ generated large inward currents (Fig. $1 B$, blue line), which slowly desensitized. In GlyT2 ${ }^{-}$neurons, these responses were abolished by strychnine $(20 \mu \mathrm{M})$ (inhibition, $98.5 \pm 1.3 \% ; n=4)$ (Fig. $1 B$, left panel, solid line). In contrast, in GlyT2 ${ }^{+}$neurons, a stationary strychnine-insensitive current remained, with a mean amplitude of $-43.5 \pm 6.8 \mathrm{pA}(n=14)$ (Fig. $1 B$, right panel, solid line). This residual current displayed the hallmarks of a transporter current because it was reversibly blocked by a specific GlyT2 inhibitor ( $5 \mu \mathrm{M}$ ORG25543; inhibition, $97.9 \pm 1.4 \% ; n=5$ ) (Fig. $1 C$ ) and did not reverse between

-100 and $+30 \mathrm{mV}$ (Fig. $1 \mathrm{D}$ ), as expected for a tightly coupled transporter. This recording of a glycine transporter current validated the fluorescence identification of GlyT2-expressing neurons in our spinal cord cultures.

\section{GlyT2 determines the neuronal glycinergic phenotype}

To examine synaptic transmission in GlyT2 ${ }^{+}$neurons, we recorded evoked postsynaptic currents (IPSCs) in pairs of connected neurons with an identified GlyT2 ${ }^{+}$presynaptic element (Fig. 2A). Presynaptic APs were triggered in current clamp by injection of depolarizing current pulses and IPSCs were recorded in connected voltage-clamped neurons $\left(13 \mathrm{GlyT}^{+}\right.$and 3 GlyT2 $^{-}$) (Fig. 2A). The strength of synaptic transmission was variable between pairs (range, -35 to $-2900 \mathrm{pA} ; n=16$ ), although the low coefficient of variation ( $\mathrm{CV}$ of $0.2 \pm 0.03$ ), the short latency $(1.6 \pm 0.1 \mathrm{~ms})$, and the absence of failures all indicated that the connections were monosynaptic. SR95531, a specific $\mathrm{GABA}_{\mathrm{A}}$ receptor antagonist at $5 \mu \mathrm{M}$, blocked one-quarter of the IPSC amplitude $(26.3 \pm 3.3 \%$; $n=30)$, whereas the remaining current was completely eliminated by strychnine (Fig. $2 \mathrm{~B}, \mathrm{C}$ ).

The majority of GlyT2 ${ }^{+}$neurons (27 of 30 ) displayed a dominant $(>50 \%)$ glycinergic phenotype (Fig. $2 D$ ), whereas the evoked postsynaptic currents of GlyT2 ${ }^{-}$presynaptic neurons were either purely GABAergic, with a single component sensitive to SR95531 ( $n=5$ of 9), or glutamatergic, with evoked currents entirely blocked by a combination of NBQX and D-APV ( $n=4$ of 9; data not shown).

Having characterized control inhibitory transmission, we first investigated the role of GlyT2 by preincubating the cultures with ORG25543, a specific GlyT2 inhibitor (Caulfield et al., 2001). Inhibition of GlyT2 by ORG25543 for 12-24 h led to an increase in the weighted decay time constant of the evoked IPSC, from $23.0 \pm 3.2 \mathrm{~ms}(n=29)$ in control neurons to $50.6 \pm 7.3 \mathrm{~ms}(n=$ $24)$ in ORG25543-incubated neurons $(p<0.001)$ (Fig. $2 F)$. However, the average decay time constant of the glycinergic component decreased from $12.5 \pm 1.0 \mathrm{~ms}(n=30)$ in control to $9.8 \pm$ $1.0 \mathrm{~ms}(n=20)$ in ORG25543-treated $(p<0.03)$ neurons (Fig. $2 B-F)$. This suggests an inversion in the relative contributions of fast glycinergic and slow GABAergic currents to the IPSCs. Indeed, the peak amplitude of the glycinergic component of the IPSCs decreased from $-680 \pm 111 \mathrm{pA}(n=30)$ in control to $-213 \pm 51 \mathrm{pA}(n=26)$ in ORG25543-treated $(p<0.001)$ neurons (Fig. $2 E$ ), whereas the amplitude of the GABAergic component increased significantly from $-264 \pm 59 \mathrm{pA}(n=30)$ to $-481 \pm 100 \mathrm{pA}(n=26 ; p<0.02)$ (Fig. $2 E)$. Furthermore, the decay time constant of the GABAergic IPSC increased from $36.4 \pm 4.5 \mathrm{~ms}(n=26)$ to $53.5 \pm 7.7 \mathrm{~ms}(n=21 ; p<0.02)$ (Fig. $2 F$ ), suggesting an increase in released GABA (Jones and Westbrook, 1995). This phenotypic switch from dominant glycinergic to dominant GABAergic (Fig. 2C,D) was of presynaptic origin because the whole-cell current amplitude evoked by glycine ( 200 $\mu \mathrm{M})$ was similar in control $(-4.0 \pm 0.5 \mathrm{nA} n=7)$ and ORG25543-treated $(-3.8 \pm 0.4 \mathrm{nA} ; n=5 ; p>0.1)$ neurons. Therefore, the reduction in amplitude of glycinergic IPSCs reflected a decrease in the amount of neurotransmitter released. Formally, this reduction could occur via one or both of two mechanisms: reduction in the number of glycinergic vesicles released (quantal content) or of their glycine content (quantal size).

\section{Chronic GlyT2 inhibition reduces glycine quantal size}

To determine whether the quantity of glycine in vesicles was reduced by preincubation with ORG25543, we recorded glycinergic mIPSCs in control and ORG25543-treated cells. Recordings 
were performed in nominally glycine-free solution to prevent reaccumulation of glycine by the cells. Glycinergic mIPSCs isolated in the presence of TTX, NBQX, D-APV, and SR95531 (Fig. 3A) were severely reduced in neurons preincubated overnight with ORG25543 compared with control neurons (Fig. 3A-C), with a $39 \%$ decrease of the mean mIPSC amplitude, from $-48.9 \pm 3.7 \mathrm{pA}(n=41)$ to $-29.8 \pm$ $0.9 \mathrm{pA}(n=57 ; p<0.001)$. The time course of mIPSCs was faster in ORG25543-treated neurons $(5.0 \pm 0.24$ $\mathrm{ms} ; n=57)$ than in control neurons $(6.1 \pm$ $0.32 \mathrm{~ms} ; n=41 ; p<0.01$ ) (Fig. $3 C$ ). Nevertheless, the main effect of GlyT2 inhibition was to decrease the MIPSC frequency, from $3.6 \pm 0.4 \mathrm{~Hz}(n=41)$ in control neurons to $0.6 \pm 0.13 \mathrm{~Hz}(n=72 ; p<$ 0.001 ) in ORG25543 neurons (Fig. $3 B$ ). We examined whether this reduction in frequency corresponded to a decrease in mIPSC amplitude below the detection threshold by recording mIPCS in the presence of zinc (Fig. $4 A, B$ ), a positive highaffinity allosteric modulator of GlyRs (Bloomenthal et al., 1994; Laube et al., 1995; Suwa et al., 2001; Laube, 2002). In both control and ORG25543-treated neurons, addition of $1 \mu \mathrm{M}$ free zinc increased the mean amplitude of mIPSCs by $17.8 \pm$ $4 \%(n=10)$ and $12.8 \pm 6 \%(n=6)$, respectively (Fig. $4 C, D$ ). Although zinc doubled the frequency of mIPSCs in ORG25543-treated neurons (Fig. 4D), glycinergic mIPSC activity remained much lower than in control neurons (Fig. 4A-C), indicating that a large majority of synaptic vesicles in ORG25543-treated neurons do not release glycine or not enough to activate postsynaptic receptors and can therefore be considered as "glycine-empty."

To assess the specificity of ORG25543 action, we recorded glycinergic, GABAergic, and glutamatergic mPSCs successively and compared their average activity expressed as the sum of mIPSC amplitudes per unit of time. Although the cumulative glycinergic mIPSC activity showed a 96\% reduction, from $5.1 \pm$ $1.6 \mathrm{nA} / \mathrm{min}(n=9)$ in control to $0.22 \pm 0.07 \mathrm{nA} / \mathrm{min}(n=11)$ in ORG25543-treated neurons (Fig. $3 D, p<0.01$ ), the average GABAergic activity increased from $0.65 \pm 0.28$ to $0.99 \pm 0.32$ $\mathrm{nA} / \mathrm{min}$ (Fig. $3 D, p>0.1$ ) primarily attributable to an increase in GABAergic mIPSC frequency (Fig. $3 E$ ), although the difference was not statistically significant. The average glutamatergic mEPSC activity was similar in control and ORG25543-treated neurons $(8.9 \pm 1.7 \mathrm{nA} / \mathrm{min}, n=9$ and $9.3 \pm 1.7 \mathrm{nA} / \mathrm{min}, n=11$ for control and ORG25543-treated neurons, respectively) (Fig. $3 E, p>0.5)$, with no statistical difference in amplitude or frequency (Fig. 3E).

To examine whether preincubation with ORG25543 in some way altered exocytosis and/or endocytosis, neurons were loaded with FM 4-64 and their fluorescence was analyzed using conventional imaging techniques (Gaffield and Betz, 2006) at individual GlyT2 $^{+}$boutons identified by the colocalization of FM 4-64 puncta and EGFP fluorescence (Fig. 3F). Comparable FM 4-64 fluorescence intensities were detected in control and ORG25543- treated neurons $(24.1 \pm 3.8$ vs $25.8 \pm 3.3$ arbitrary units, respectively; $p>0.5$ ), indicating similar rates of vesicle endocytosis during the loading phase. During repetitive high-frequency stimulation (HFS) $(10 \mathrm{~Hz}$ for $1 \mathrm{~min})$, rapid destaining of fluorescence-labeled vesicles was observed. This destaining was not detected in the presence of TTX, indicating that it was dependent on action potentials (Fig. 3G). Similar reductions in fluorescence were observed in response to HFS at individual boutons of control $(59 \pm 6 \% ; n=6)$ and ORG25543-treated $(56 \pm 4 \% ; n=$ $6 ; p>0.4)$ neurons.

These results strongly suggest that preincubation with ORG25543 reduced glycinergic quantal size and apparent quantal number via a reduction of vesicle filling. This effect appeared to be specific, because ORG25543 had no (or the opposite) effect on glutamatergic and GABAergic mPSCs and did not detectably alter vesicular endocytosis or exocytosis.

\section{Restoration of mIPSCs by GlyT2-mediated glycine uptake}

It seemed probable that GlyT2 inhibition acted on vesicular glycine content via a diminution of the cytosolic glycine concentration. This mechanism predicts that resupplying glycine to the transporter might restore mIPSCs. We tested this prediction by applying $100 \mu \mathrm{M}$ glycine for $10 \mathrm{~min}$ (in the presence of strychnine to limit glycine receptor-mediated chloride fluxes) (Fig. 5A). In control neurons, the average amplitude of mIPSCs was the same before and after glycine application $(-45.3 \pm 3.2$ and $-45.2 \pm$ $4.4 \mathrm{pA}$, respectively; $n=16)$. In contrast, we observed a remarkable restoration of mIPSC activity in ORG25543-treated neurons 

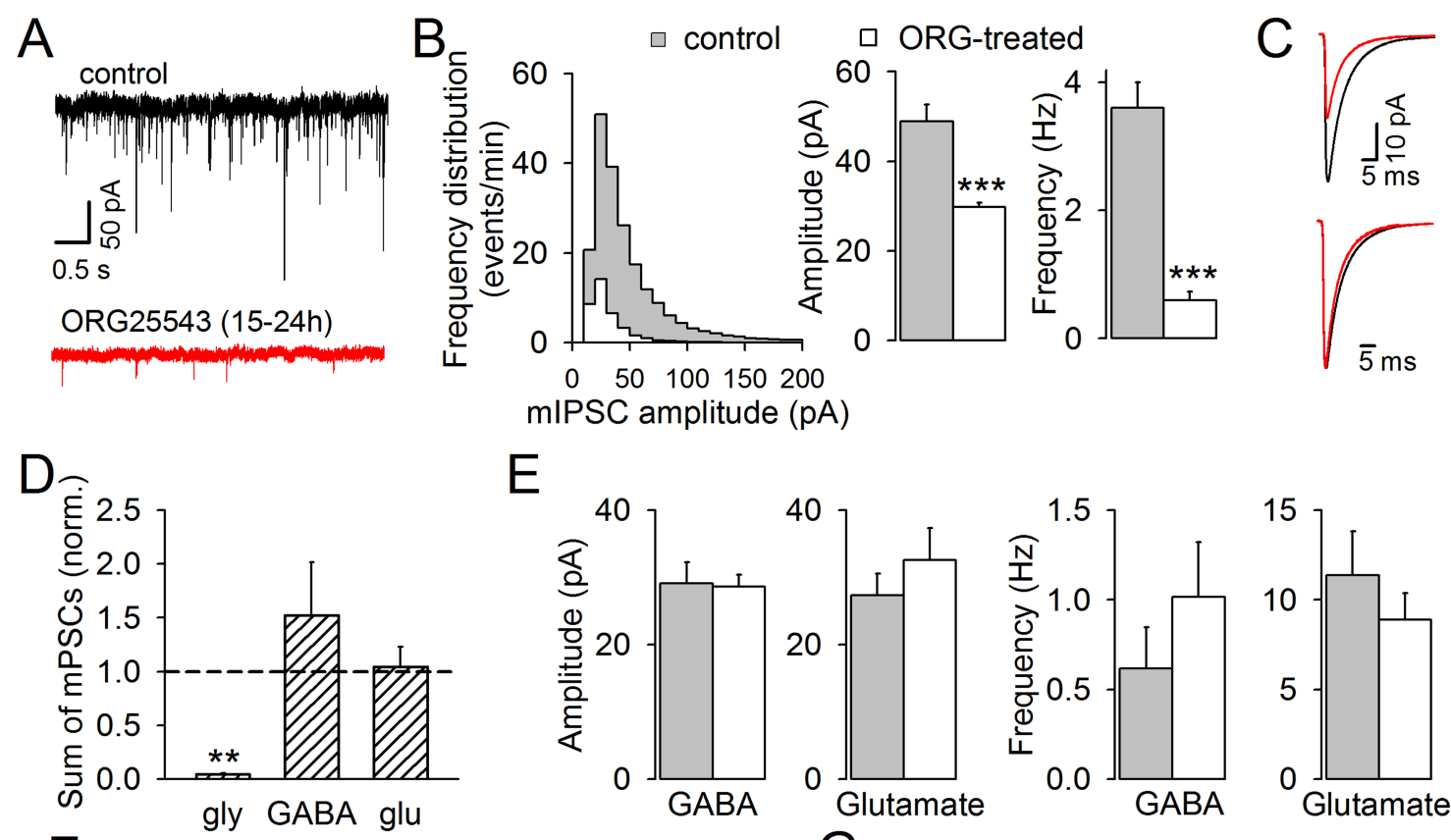

E

$\mathrm{F}$
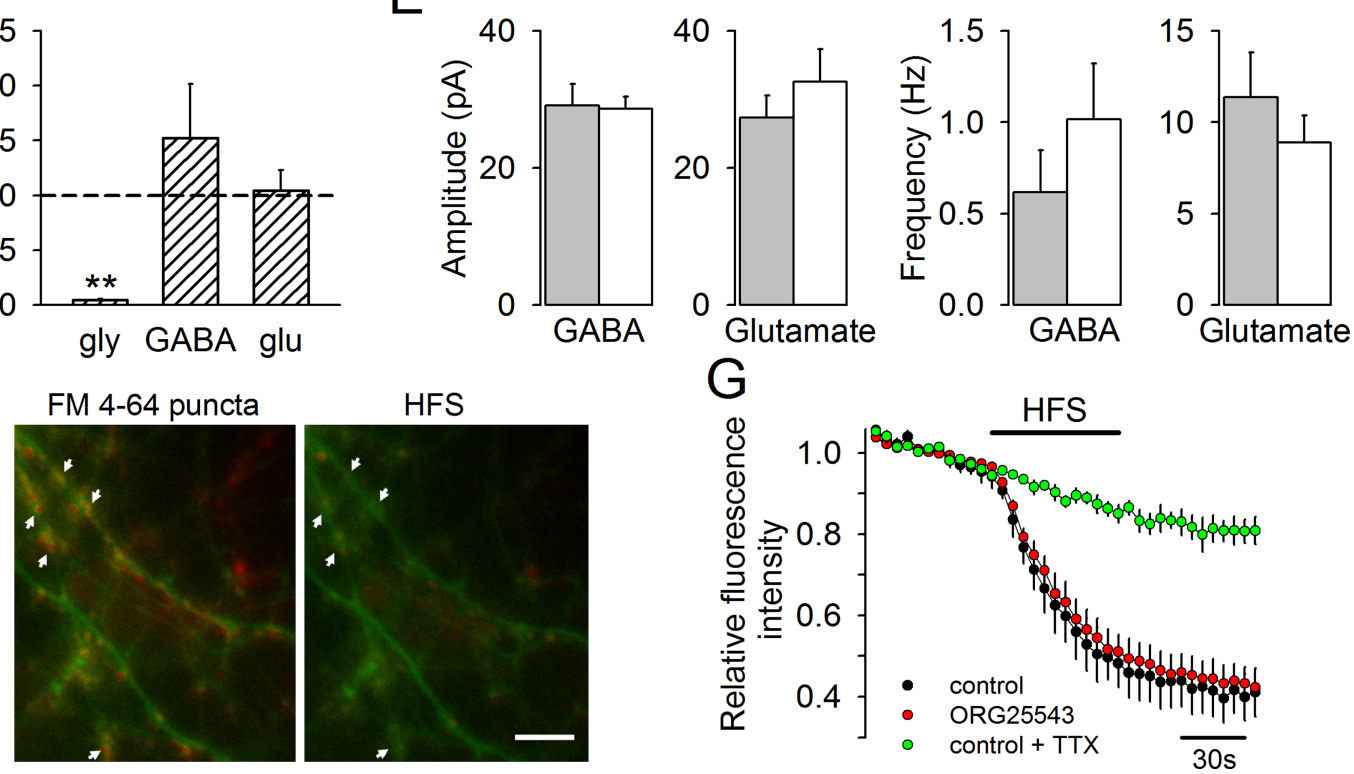

Figure 3. Chronic GlyT2 inhibition reduces glycine quantal size. $A$, Traces of glycinergic mIPSCs recorded from a control neuron (top trace, solid line) and from a neuron preincubated with $5 \mu \mathrm{M}$ ORG25543 for 15-24 h (bottom trace, red line). $\boldsymbol{B}$, Left, Distributions of mIPSC amplitude in control neurons (gray; $n=41$ ) and in 0RG25543-treated neurons (white; $n=72 ; p<0.001$ ). Right, Bar graphs of the amplitude and frequency of mIPSCs recorded in control neurons (gray; $n=41$ ) and in 0RG25543-treated neurons (white; $n=57$ for amplitude and $n=72$ for frequency; $p<0.001$ ). C, Raw (top traces) and normalized (bottom traces) average mIPSCs recorded in control neurons ( $n=41$; solid line) and 0RG25543-treated neurons ( $n=57$; red line). $\boldsymbol{D}$, Bar graph of the sum of amplitudes per minute of glycinergic, GABAergic, and glutamatergic mPSCs recorded in the presence of NBQX + D-APV + SR95531, NBQX + D-APV + strychnine, and SR95531 + strychnine, respectively, for neurons preincubated with ORG25543 $(n=11)$. Data are normalized to values obtained with control neurons $(n=9)$. $\boldsymbol{E}$, Bar graphs of the amplitude and frequency of GABAergic and glutamatergic $\mathrm{mPSC}$ recorded in control neurons (gray; $n=11$ ) and in 0RG25543-treated neurons (white; $n=9 ; p>0.05$ ). $\boldsymbol{F}$, Left, Visualization of synaptic boutons (arrows) in GlyT2 ${ }^{+}$ neurons after FM 4-64 loading. Right, Destaining of FM 4-64 fluorescence after HFS (10 Hz, 1 min). Scale bar, $10 \mu \mathrm{m}$. G, Time course of the change in FM 4-64 fluorescence induced by HFS in control neurons (filled circle; $130-190$ boutons/coverslips; $n=6$ ) and neurons preincubated with $5 \mu \mathrm{m}$ ORG25543 (red circle; $110-220$ boutons/coverslips; $n=6 ; p>0.1$ ). HFS did not induce a change in FM 4-64 fluorescence in the presence of TTX (green circle; $110-150$ boutons/coverslips; $n=4$ ).

(Fig. 5A-C). The amplitude of mIPSCs returned rapidly to the control level (Fig. $5 B$ ), from $-28.2 \pm 1.2$ to $-42.8 \pm 4.0 \mathrm{pA}(n=$ 20 ), with very similar cumulative distributions (Fig. $5 C, p>0.5$ ). The relative change in mIPSCs amplitude, frequency, and time constant induced by glycine is shown in more detail for individual cells in supplemental Figure 1 (available at www.jneurosci.org as supplemental material).

This almost complete restoration of transmission further strengthens the conclusion that GlyT2 acts exclusively via control of intracellular glycine, which in turn regulates vesicular filling. To check the specificity of the restoration for glycine transmission and to exclude any role for the small tonic activation of GlyRs during glycine application, glycine $(100 \mu \mathrm{M})$ was replaced by $\beta$-alanine or taurine $(200 \mu \mathrm{M})$, both GlyR agonists (Lynch, $2004)$ that are weak ( $\beta$-alanine) or not (taurine) substrates of GlyT2 (supplemental Fig. 2, available at www.jneurosci.org as supplemental material). When applied in the presence of strychnine $(3 \mu \mathrm{M}), \beta$-alanine and taurine evoked a small and noisy GlyR-mediated current (data not shown) similar to that evoked by glycine but failed to restore mIPSC activity in ORG25543treated neurons (Fig. 5D,E). Furthermore, when glycine was applied in the presence of ORG25543 $(5 \mu \mathrm{M})$, the mIPSC activity remained unchanged after complete washout of strychnine (Fig. $5 E)$. The restoration of mIPSCs by glycine displayed the expected pharmacological profile because, of the drugs tested, only glycine is a substrate for both GlyT2 and the vesicular transporter VIAAT at the concentration applied. These results show that ORG25543 pretreatment selectively and specifically reduces glycine accumulation and thus reduces vesicular glycine content. This effect can be fully reversed by the brief uptake of extracellular glycine by GlyT2.

As the amplitude of mIPSCs in control neurons were not potentiated by glycine uptake (Fig. $5 B$ ), we examined whether there was a presynaptic change in glycine release by taking advantage of SR95531, a low-affinity competitive antagonist of GlyRs (Wang and Slaughter, 2005; Beato et al., 2007). Inhibition of GlyRs by a competitive antagonist should be sensitive to changes in the amount of glycine released (Clements, 1996) because SR95531 
has an estimated mean lifetime occupancy of $300 \mu$ s and should unbind within the timescale of synaptic release (Beato et al., 2007). In outside-out or nucleated patches, SR95531 at $70 \mu \mathrm{M}$, a concentration well below its binding equilibrium constant of $190 \mu \mathrm{M}$ (Beato et al., 2007), blocked the current evoked by $60 \mu \mathrm{M}$ glycine by $61 \pm 11 \%(n=3)$, whereas the current evoked by $200 \mu \mathrm{M}$ glycine was reduced only by $10.6 \pm 9.5 \%$ (data not shown). To mimic fast synaptic release, we recorded currents evoked by brief $1 \mathrm{~ms}$ iontophoretic applications of glycine and confirmed that the fraction of the current blocked by $70 \mu \mathrm{M}$ S95531 decreased as the amount of glycine release increased (Fig. $6 A$ ). Figure $6 B$ shows that $70 \mu \mathrm{M}$ SR95531 reduced the amplitude of glycinergic $\mathrm{mIP}$ SCs by $28.6 \pm 2 \%(n=6)$ (Fig. $6 B, C)$ and that this block remained unchanged $(29.9 \pm 1 \% ; n=6)$ (Fig. $6 D, E$ ) after glycine application $(100 \mu \mathrm{M}$ for $10 \mathrm{~min}$ in the presence of $3 \mu \mathrm{M}$ strychnine), suggesting that there was no significant change in glycine released after GlyT2 uptake in control neurons.

\section{Acute depletion of intracellular glycine and its reversal}

To deplete the intracellular storage of glycine, the ORG25543 preincubation protocol described above lasted 15-24 h. We wanted to test whether acute manipulation of intracellular glycine levels could induce similar effects. We tested this by exploiting the dialysis of the cytoplasm by the patch pipette. In the absence of intracellular or extracellular glycine, the evoked synaptic response ran down during continuous stimulation at $1 \mathrm{~Hz}$ over a period of $30 \mathrm{~min}$ (Fig. $7 A$ ) $[87 \pm 3 \%$ reduction $(n=20)$ compared with a basal rundown of $21.6 \pm 11.6 \%(n=4)$ in the absence of repeated stimulation]. The time course of this rundown was quite variable between cells, ranging from complete disappearance in $15 \mathrm{~min}$ to incomplete inhibition after $60 \mathrm{~min}$ (Fig. $7 C)\left(t_{80-20}=28 \pm 4 \mathrm{~min} ; n=20\right)$. A sharp acceleration in the time course was present after $\sim 20 \mathrm{~min}$ of stimulation in 7 of 20 pairs, suggesting that the dialysis of glycine in the axon terminals became effective only after a long latency (Mathias et al., 1990).

Once the rundown had occurred, the response did not recover even if the stimulation frequency was reduced to a very low rate $(0.1 \mathrm{~Hz}$; the frequency dependence of the transmission is investigated below). However, application of $100 \mu \mathrm{M}$ glycine (in the presence of strychnine) induced a strong recovery of the evoked response to $77 \pm 13 \%$ of the initial amplitude $(n=10)$ (Fig. $7 B)$. The time course of the recovery was masked by the presence and long wash out of strychnine. Surprisingly, the IPSC decay time constant increased from $12.3 \pm 2.0 \mathrm{~ms}(n=10)$ to $19.9 \pm 3.1 \mathrm{~ms}$ $(p<0.05)$ after recovery after glycine. Moreover, preventing the loss of glycine by addition of a high concentration of glycine in the intracellular solution limited the run down to $57 \pm 8 \%$ of the

\section{control neuron}

- zinc

$+\operatorname{zinc}(1 \mu \mathrm{M})$
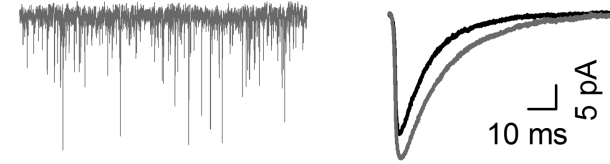

$\frac{⿱}{\varrho}$

$0 \mathrm{~ms}$

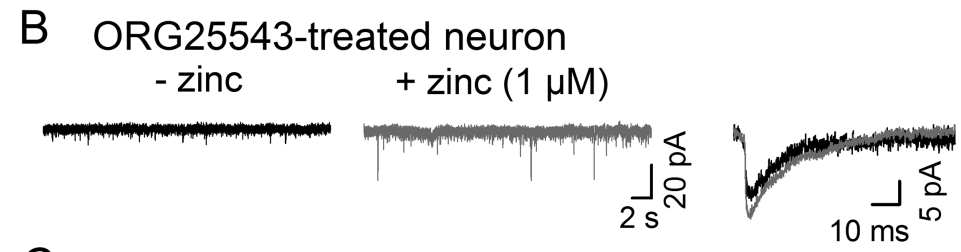

control neuron

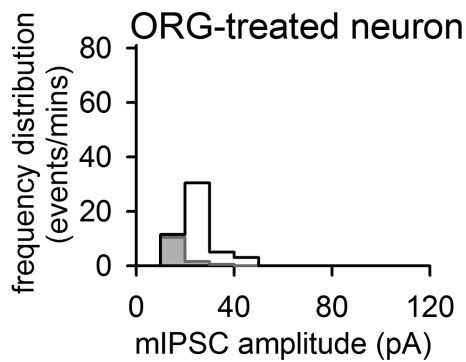

mIPSC amplitude (pA)

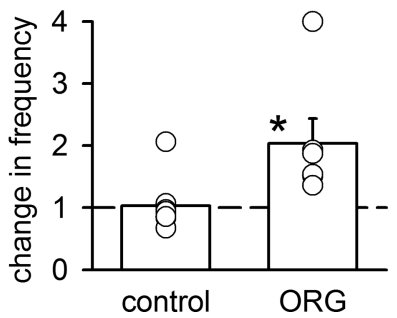

control ORG

Figure 4. Zinc unmasks a small population of vesicles containing trace levels of glycine in ORG25543-treated neurons. Glycin25543-treated neurons ( $n=10$ for controlneurons, $p<0.5 ; n=6$ for 0 RG-treated neurons; $p>0.5$ ). Zinchad no on mIPSC frequency in control neurons $(n=10 ; p>0.5)$ but always increased the mIPSC frequency in 0RG25543-treated neurons $(n=6 ; p<0.5)$, suggesting that small events were below the detection threshold.

initial amplitude $(n=4 ; p<0.02)$ after 30 min of dialysis (Fig. 7C).

Therefore, it is possible to acutely deplete and restore intracellular glycine levels, and these effects are consistent with those produced by chronic GlyT2 inhibition (Figs. 2, 3).

\section{Glycine supply during high-frequency activity}

A crucial role of glycine uptake is to supply neurotransmitter to fill newly formed vesicles and refill those recovered by endocytosis. To investigate the role of GlyT2 in this process, we recorded glycinergic IPSCs evoked by high-frequency stimulation and identified two phases of stationary release. Figure $8 A-C$ shows the traces of IPSCs from a paired recording that was stimulated with $1000 \mathrm{APs}$ at $5 \mathrm{~Hz}$. IPSCs recorded during initial and late phase of the stimulation had the same kinetics, but the amplitude of late IPSCs was reduced (Fig. 8C). The average time course of IPSC amplitude during stimulation is shown in more detail in Figure $8 D$, using a logarithmic timescale. The very first IPSC $\left(I_{1}\right)$ of the train was always larger than subsequent IPSCs and was ignored because its "frequency" is 0 . Subsequent IPSCs show an 
A
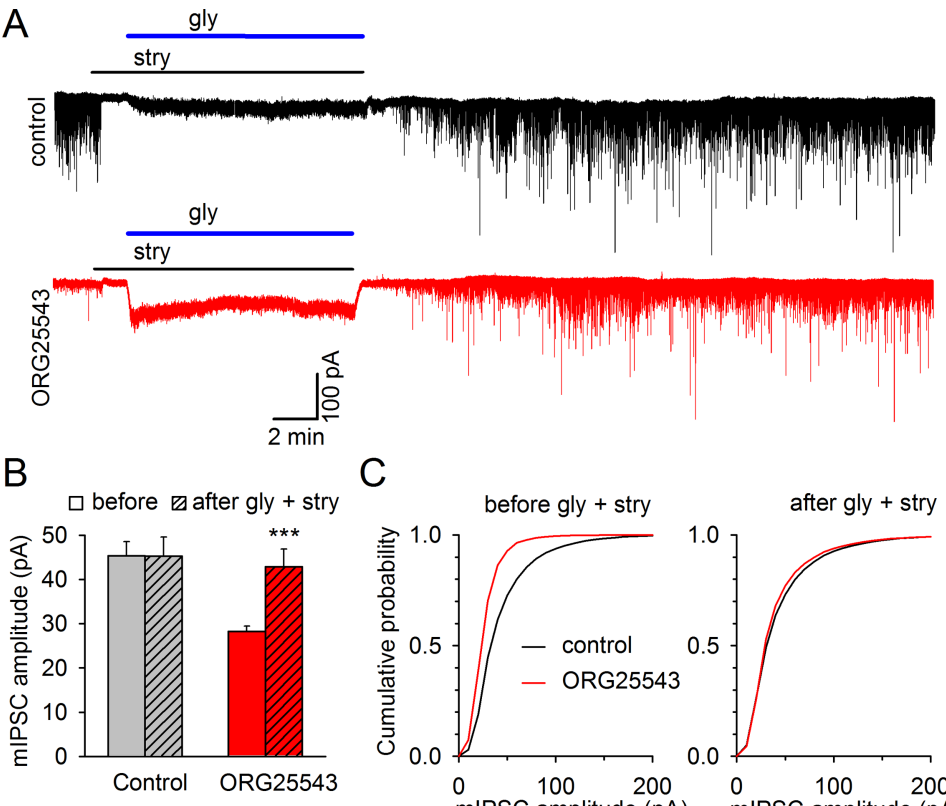

C
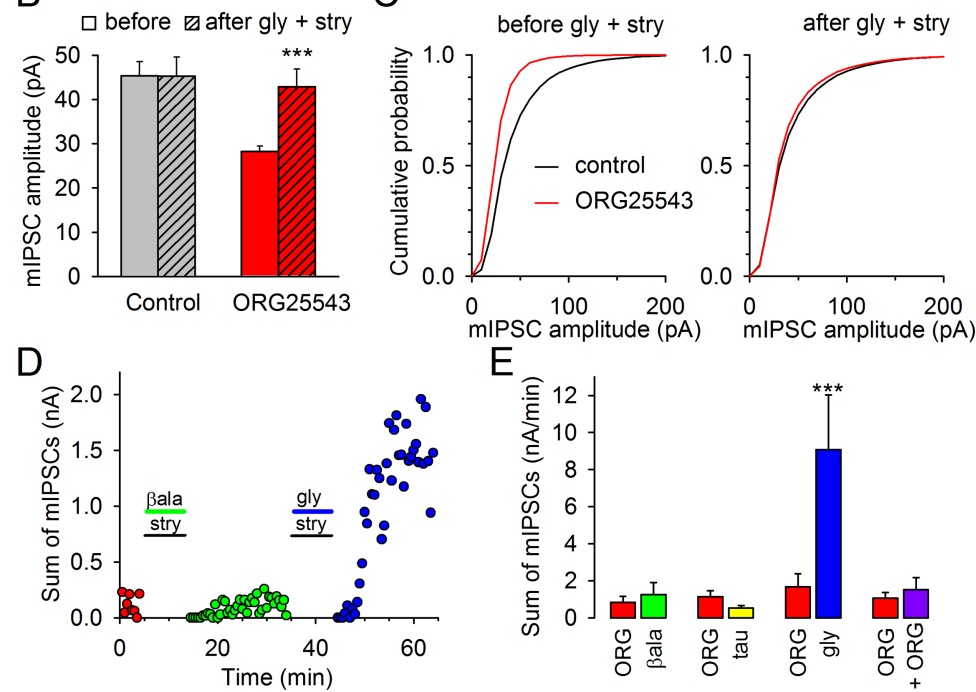

$\mathrm{E}$

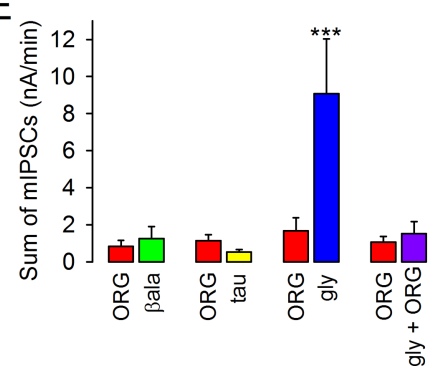

Figure 5. Glycine uptake by GlyT2 restores glycinergic mIPSCs. A, Representative traces of glycinergic mIPSCs recorded in control neurons (top, black) and in neurons preincubated with $5 \mu \mathrm{m}$ 0RG25543 for $12-24 \mathrm{~h}$ (bottom, red). Glycine (100 $\mu \mathrm{m}$; blue line) was applied in the presence of strychnine ( $3 \mu \mathrm{m}$; solid line; stry). The average tonic GlyR current evoked by glycine was comparable for control and ORG25543-treated neurons $(-37.9 \pm 4.1, n=10$ and $-40.3 \pm 4.6 \mathrm{pA}, n=17$, respectively). $\boldsymbol{B}$, Bar graphs of the mean amplitude of glycinergic mIPSCs from control neurons (gray bars; $n=16$ ) and ORG25543-treated neurons (red bars; $n=20)$, before (solid bars) and after (striped bars) glycine application with strychnine $(3,10$, or $30 \mu \mathrm{m}$, all data were pooled). C, Cumulative probability of mIPSC amplitude distribution recorded from control neurons (black line; $n=16$ ) and from glycinergic neurons preincubated with $5 \mu \mathrm{M} 0 \mathrm{RG} 25543$ for $15-24 \mathrm{~h}$ (red line; $n=20$ ) before (left; $p<0.001$ ) and after (right; $p>0.5$ ) glycine application. $\boldsymbol{D}$, Time course of the sum of $\mathrm{mIPSC}$ peak amplitudes per $30 \mathrm{~s}$ recorded from a neuron preincubated with $5 \mu \mathrm{M}$ ORG25543 for $15-24 \mathrm{~h}$. $\beta$-Alanine $(200 \mu \mathrm{M})$ and then glycine $(100 \mu \mathrm{M})$ were applied in the presence of strychnine (3 $\mu \mathrm{M})$. $\boldsymbol{E}$, Sum of glycinergic mIPS (peak amplitudes per minute in ORG25543-treated neurons (red) after application of $\beta$-alanine (200 $\mu \mathrm{m}$; green; $n=7$ ), taurine ( $300 \mu \mathrm{m} ;$ yellow; $n=4)$, glycine (100 $\mu \mathrm{m}$; blue; $n=23 ; p<0.001)$, and glycine $(100 \mu \mathrm{M})+$ ORG25543 (5 $\mu \mathrm{m})$ (purple; $n=8)$.

initial plateau (Fig. 8D) $\left(\mathrm{I}_{\mathrm{p}} / \mathrm{I}_{1}=0.62 \pm 0.01 ; n=18\right)$, typically between APs 3 and 40, and then a rundown to a low steady-state (tonic) level $\left(\mathrm{I}_{\mathrm{ss}} / \mathrm{I}_{1}=0.13 \pm 0.02\right)$. In contrast, the IPSC amplitude remained stable during the same period when stimulated at low frequency $(0.1 \mathrm{~Hz})$ (Fig. $8 D$, triangles). The reduced response in the tonic phase of $5 \mathrm{~Hz}$ stimulation could be caused by many presynaptic and/or postsynaptic mechanisms underlying shortterm plasticity (Foster and Regehr, 2004; Xu-Friedman and Regehr, 2004): lower release probability, decrease in the pool of releasable vesicle, lower vesicular glycine content, or GlyR desensitization (Rigo and Legendre, 2006). Nevertheless, we were interested to examine whether the rate of vesicle refilling with glycine played a role during tonic release. In principle, some information about the locus of the synaptic depression can be obtained from the coefficient of variation method by comparing initial and late release events (Faber and Korn, 1991; Foster and Regehr, 2004). The average reduction in IPSC amplitude was inversely proportional to the variation in $\mathrm{CV}^{2}$ (Fig. $8 E$ ), thus arguing against a uniform reduction of quantal size and hence against uniform desensitization or reduction of glycine content being the major cause for the reduction in amplitude during high-frequency stimulation. Directly sampling quanta by recording asynchronous IPSCs (aIPSCs) using strontium showed a reduction in aIPSC amplitude between initial and late release, from $-58.6 \pm 9.6$ to $-38.7 \pm 4.3 \mathrm{pA}(n=5 ; p>$ 0.05 ) (supplemental Fig. 3, available at www.jneurosci.org as supplemental material), but this reduction cannot account for the extent of synaptic depression. We did not investigate further other mechanisms, except to exclude a reduction in release probability by the activation of presynaptic $\mathrm{GABA}_{\mathrm{B}}$ receptors by coreleased GABA (Lim et al., 2000), because similar synaptic depressions were recorded in the presence of CGP55845 (0.25 and $1 \mu \mathrm{M}$ ) (supplemental Fig. 4, available at www. jneurosci.org as supplemental material), a specific $\mathrm{GABA}_{\mathrm{B}}$ receptor antagonist (Blake et al., 1993).

In contrast to the slow rundown produced by whole-cell dialysis (Fig. 7), synaptic depressions evoked by highfrequency stimulation were reversible. Figure $8 F$ shows the amplitude of IPSCs from a paired recording in which 0.1 and 5 $\mathrm{Hz}$ stimulation periods were interleaved. The low-frequency responses (Fig. $8 F$, triangles) chart the progressive depletion of intracellular glycine. The decrease in cumulative IPSC amplitude in four consecutive trials showed a progressive decline in initial and late tonic responses (Fig. 8G). Because both initial and late responses might include the release of slowly recruited and/or recycled vesicles, their codecline suggests the capacity to refill recycled vesicles with glycine decreased as the rundown progressed.

Next, we examined whether GlyT2-mediated uptake could restore high-frequency release in glycine-depleted neurons. To do so, two trains of $1000 \mathrm{APs}$ at $5 \mathrm{~Hz}$ were evoked before and after glycine application in dialyzed and ORG25543-treated neurons, our two models of glycine depletion. Figure $9 A$ shows the time course of IPSC amplitude in a control neuron that is being dialyzed. In this cell, the slow rundown took $3000 \mathrm{APs}$ evoked at $1 \mathrm{~Hz}$ (the average IPSC amplitude was computed every minute in Fig. $9 A$, gray circles). Subsequent application of glycine effectively potentiated the responses evoked by low-frequency stimulation (Fig. 9A, triangles), whereas the late phase of release was not restored during the second $5 \mathrm{~Hz}$ stimulation $\left(\mathrm{I}_{\mathrm{ss}} / \mathrm{I}_{\mathrm{p}}=0.018 \pm\right.$ 0.007; $n=3$ ) (Fig. 9A,B). Indeed, the cumulative amplitude of the second stimulation approached saturation after $\sim 200$ APs (Fig. 9C, green line), in contrast to the continuous rise observed during the first train (Fig. 9C, blue line). A similar result was obtained using ORG25543-treated cells that were already 
glycine-depleted at the onset of the experiment (Fig. 9D,E,H). Once again, glycine uptake strongly potentiated the response evoked at low frequency and during the initial phase of high-frequency stimulation (Fig. 9D, E, G,I) but failed to potentiate the late tonic phase $\left(\mathrm{I}_{\mathrm{ss}} / \mathrm{I}_{\mathrm{p}}=0.059 \pm\right.$ $0.037 ; n=4)$ as shown by the saturating value of cumulative amplitude (Fig. 9F, green line).

The failure of GlyT2-mediated uptake to restore tonic synaptic release suggested that glycine did not reach the cytosolic concentration needed for efficient VIAAT loading, thus reducing the rate of vesicle refilling. To test this hypothesis, similar experiments were repeated with a presynaptic intracellular solution containing high concentrations of glycine (10 or 20 $\mathrm{mM}$ ). Figure $10 \mathrm{~A}$ shows a trace of IPSCs evoked by $5 \mathrm{~Hz}$ stimulation in a neuron dialyzed with a pipette solution containing $10 \mathrm{~mm}$ glycine. Although a synaptic depression was still present during the highfrequency stimulation, the mean amplitude of the last 200 IPSCs was potentiated by the addition of glycine in the pipette solution (Fig. $10 A-C$ ), from $\mathrm{I}_{\mathrm{ss}} / \mathrm{I}_{\mathrm{p}}=$ $0.18 \pm 0.03(n=16)$ in the absence of glycine to $0.34 \pm 0.07(n=7 ; p<0.05)$ and $0.52 \pm 0.07(n=4 ; p<0.01)$ in the presence of 10 and $20 \mathrm{~mm}$ glycine, respectively (Fig. 10C). The cumulative amplitudes of IPSCs during $5 \mathrm{~Hz}$ stimulation (normalized to the initial amplitude) plotted in Figure $10 \mathrm{D}$ allow a direct comparison of the five different conditions of glycine supply described above. The slopes of cumulative amplitude during the tonic phase of release (after $\sim 200$ APs) rise with increasing glycine concentration (Fig. 10D, solid lines), suggesting that VIAAT kinetics limits the refilling of vesicles with glycine. Therefore, the absence of tonic release in dialyzed and ORG25543-treated neurons after short-term glycine uptake (Fig. $10 \mathrm{D}$, dashed lines) may be explained by a lower cytosolic glycine concentration and thus lower rate of vesicles refilling.

Finally, we examined whether the uptake of glycine by GlyT2, at a concentration $(5 \mu \mathrm{M})$ near physiological levels, can support vesicle refilling. As shown previously in Figure 9D, the initial pool of glycinergic vesicles was exhausted in ORG25543-treated cells after high-frequency stimulation (Fig. $11 \mathrm{~A}$ ). Then the amplitude of IPSCs were monitored at low frequency $(0.1 \mathrm{~Hz})$ in the presence or absence of extracellular glycine $(5 \mu \mathrm{M})$ (Fig. $11 \mathrm{~A})$. Because $5 \mu \mathrm{M}$ glycine evoked only a small tonic current $(-49.2 \pm 11$ $\mathrm{pA} ; n=7$ ), addition of strychnine was not necessary, thus unmasking the coupling between uptake and release. During glycine application, the amplitude of IPSCs rose slowly, reflecting the growth in the pool of vesicles refilled with glycine (Fig. $11 \mathrm{~A})$. We estimated that IPSC amplitude increased by $63 \pm 10 \%(n=7)$ after $20 \mathrm{~min}$ of $5 \mu \mathrm{M}$ glycine application (Fig. 11C). Surprisingly, the washout of glycine in five of seven pairs evoked a monotonic decline of IPSC amplitude, indicating a direct coupling between GlyT2-mediated uptake and vesicles refilled with glycine (Fig.
$11 A)$. In one tested cell, subsequent addition of glycine restored the transmission (Fig. 11A).

The time course of the IPSC was slower after glycine application (Fig. $11 B$ ) as shown previously in Figure $9 G$. In both experiments using ORG25543-treated cells, the decay time constant increased from $6.9 \pm 0.7 \mathrm{~ms}$ at the beginning of the recording to $15.8 \pm 3.8 \mathrm{~ms}(n=10 ; p<0.05)$ after recovery by glycine uptake. A hypothesis for this kinetic change will be discussed below.

\section{Discussion}

GlyT2 specifies the neuronal glycinergic phenotype

In this study, we took advantage of transgenic GlyT2-EGFP mice (Zeilhofer et al., 2005) to record evoked currents in pairs of connected spinal cord neurons with an identified GlyT2 ${ }^{+}$presynaptic element. Half of the neurons were fluorescent in the cultures, in good agreement with the $50 \%$ distribution of neurons expressing GlyT2 mRNA in laminas IV-VIII of the rat spinal cord (Hossaini et al., 2007). The probability of ectopic expression was reduced by using heterozygous GlyT2-EGFP mice (Zeilhofer et al., 2005), and we confirmed the membrane expression of GlyT2 by the observation that glycine uptake currents were only recorded in fluorescent neurons.

No strychnine-sensitive IPSCs were evoked in GlyT2 ${ }^{-}$neuron pairs, and all GlyT2 ${ }^{+}$neurons were glycinergic, confirming that GlyT2 expression is therefore necessary and sufficient to 
A

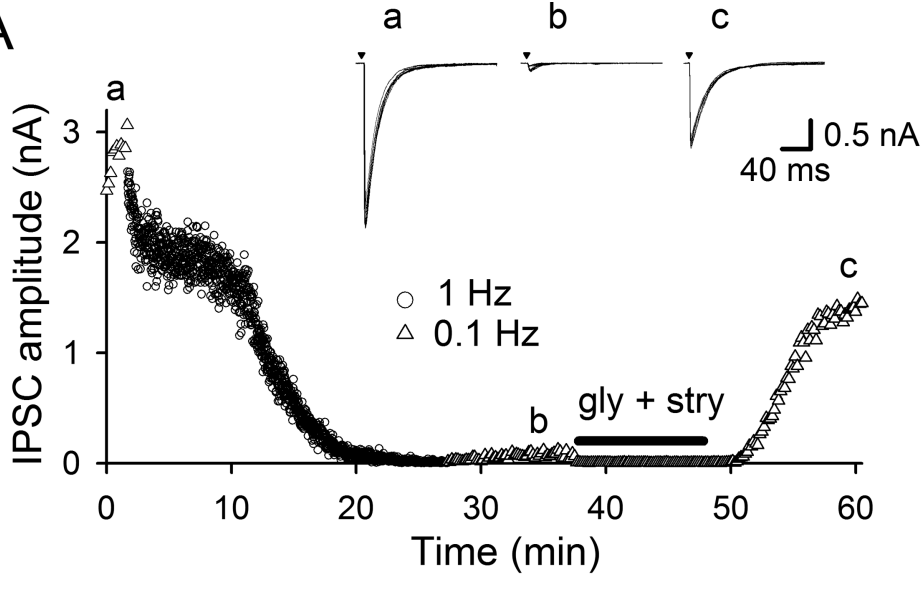

B

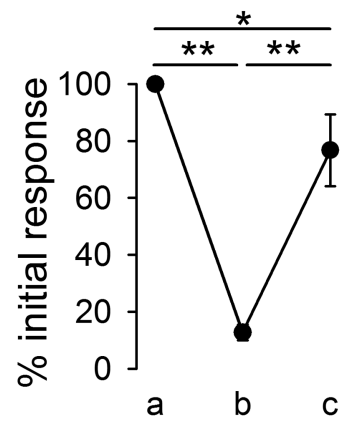

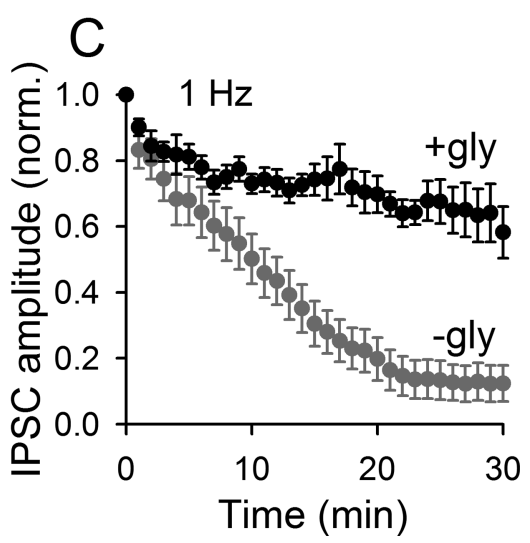

Figure 7. Acute depletion and refilling of glycine-containing vesicles by GlyT2-mediated uptake. $\boldsymbol{A}$, Time course of the depression of glycinergic IPSCs recorded from a pair with a presynaptic GlyT2 ${ }^{+}$neuron during repeated stimulation at $1 \mathrm{~Hz}$ (open circles). After near complete rundown of the transmission, the stimulation frequency was lowered to $0.1 \mathrm{~Hz}$ (open triangles) and glycine (100 $\mu \mathrm{m}$; solid line) was applied for $10 \mathrm{~min}$ in the presence of strychnine $(10 \mu \mathrm{m})$. Inset, Current traces recorded for 10 consecutive IPSCs before $1 \mathrm{~Hz}$ stimulation $(\boldsymbol{a})$, after the rundown $(\boldsymbol{b})$, and after recovery with glycine $(\boldsymbol{c})$. $\boldsymbol{B}$, Average change in IPSC amplitude recorded in 10 pairs after complete rundown $(\boldsymbol{b})$ and after glycine application $(\boldsymbol{c})$. The responses are expressed as percentage of their initial amplitude recorded in $\boldsymbol{a}$. $\boldsymbol{C}$, Time course of glycinergic IPSC rundown during repeated stimulation at $1 \mathrm{~Hz}$ when the presynaptic GlyT2 ${ }^{+}$neuron is dialyzed without (gray; $n=6$ ) or with (black circles) glycine $[p<0.02$; data from $10 \mathrm{~mm}(n=2)$ and $20 \mathrm{~mm}(n=2)$ glycine were pooled] in the pipette solution.

determine a glycinergic phenotype (Jursky and Nelson, 1995; Zafra et al., 1995; Zeilhofer et al., 2005). However, the neuronal glycinergic phenotype was always associated with a GABAergic component. These mixed phenotypes are expected from embryonic spinal cord inhibitory neurons because expression of GlyT2 overlaps with that of glutamate decarboxylase (GAD) during the development of spinal cord and brainstem nuclei (Geiman et al., 2002; Mackie et al., 2003; Tanaka and Ezure, 2004). Furthermore, corelease of GABA and glycine is the main mode of immature inhibitory transmission in these structures (Jonas et al., 1998; Chéry and de Koninck, 1999; O’Brien and Berger, 1999; Russier et al., 2002). Considering that the $\mathrm{EC}_{50}$ of VIAAT for GABA transport is lower than for glycine (McIntire et al., 1997; Bedet et al., 2000), we interpret the dominance of glycinergic transmission in the majority of the synapses made by GlyT2 ${ }^{+}$neurons as reflecting a much higher supply of glycine (by uptake) than of GABA (by synthesis). Nevertheless, part of this glycinergic dominance could be also accounted for by differences in the relative expression or stabilization of the GlyR and $\mathrm{GABA}_{\mathrm{A}} \mathrm{R}$ in postsynaptic clusters (Todd et al., 1996), as shown in the cerebellum for the two targets of the Golgi cell (Dugué et al., 2005).

Blocking neuronal glycine uptake for several hours markedly

reduced glycinergic transmission in culture, as in slices (Gomeza et al., 2003; Bradaïa et al., 2004), but enhanced GABAergic transmission. The combination of these changes was sufficient to shift the neuron phenotype from mostly glycinergic to mostly GABAergic (Fig. 2D), thus illustrating the pivotal role of GlyT2 for the developmentally regulated switch of inhibitory phenotypes detected in many brainstem and spinal cord structures (Kotak et al., 1998; Gao et al., 2001; Keller et al., 2001). For example, in the lateral superior olive (LSO), a brainstem auditory nucleus, a transition from GABAergic to glycinergic transmission occurs during the second postnatal week (Kotak et al., 1998; Awatramani et al., 2005) that is associated with the formation of punctuate clusters of GlyT2 around LSO neurons (Zafra et al., 1995; Friauf et al., 1999) and a downregulation of glutamate decarboxylase ( $\mathrm{Na}$ bekura et al., 2004). Interestingly, the peak of GlyT2 expression in the LSO is observed at postnatal day 10, near the onset of the shift (Kotak et al., 1998; Friauf et al., 1999; Awatramani et al., 2005), and then decreases, presumably because of lower competition of glycine with GABA (Nabekura et al., 2004).

\section{Glycine and GABA content in synaptic vesicles}

The experiments with FM 4-64 dye indicated that the recycling of synaptic vesicles was not impaired in ORG25543-treated neurons, thus confirming that recycling and refilling of vesicles are not tightly coupled (Edwards, 2007). Vesicles were not expected to be empty in ORG25543treated neurons because glycine and GABA are thought to substitute for one another when their relative concentrations are changed, as both amino acids are coaccumulated in the same VIAAT-containing vesicles (Wojcik et al., 2006; Aubrey et al., 2007). However, restarting GlyT2-mediated glycine uptake in neurons treated overnight with ORG25543 restored miniature and evoked glycinergic IPSC amplitude within $10 \mathrm{~min}$, suggesting that glycine-free vesicles were not completely filled with GABA, because they could be filled to control levels with glycine when it became available. Alternatively, glycine may replace GABA in vesicles if VIAAT mediates rapid exchange of the two amino acid neurotransmitters.

Manipulations that augment GABA supply in brain slices, by either reducing its degradation (Engel et al., 2001) or providing glutamate for GABA synthesis (Mathews and Diamond, 2003), increase the amplitude of GABAergic mIPSCs. In contrast, we show that glycine application did not potentiate the amplitude of glycinergic mIPSCs in control neurons and restored only to the level of control neurons in glycine-depleted ORG25543-treated neurons (Fig. 5C). These results can be explained by a saturation of postsynaptic GlyRs or alternatively by a saturation in the amount of glycine that can be stored in vesicles. In agreement with previous studies (Suwa et al., 2001; Laube, 2002; Rigo et al., 
2003; Hirzel et al., 2006), we provide evidence that GlyRs are not saturated in our preparation because the MIPSCs were potentiated by $1 \mu \mathrm{M}$ zinc, a high-affinity allosteric modulator that increases the receptor affinity for glycine (Bloomenthal et al., 1994; Laube et al., 1995, 2000; Suwa et al., 2001; Miller et al., 2005). The fraction of the current blocked by SR95531 did not change after glycine uptake, suggesting that increasing glycine availability does not increase vesicular accumulation of glycine in control neurons.

Although glycine and GABA transport by VIAAT are presumably coupled to the same exchange with $1 \mathrm{H}^{+}$(Burger et al., 1991; Edwards, 2007), their accumulation in synaptic vesicles may not be limited by the same thermodynamic or kinetic constraints if their cytosolic concentrations differ significantly. Glycine content measured in mice spinal cord tissues $(\sim 4$ $\mu \mathrm{mol} / \mathrm{mg}$ protein) (Daly, 1990) is approximately two orders of magnitude larger than GABA content measured in the cortex of adult mice $(\sim 15 \mathrm{nmol} / \mathrm{mg}$ protein) (Asada et al., 1997). Furthermore, glycine loading during vesicle reacidification might be faster than for GABA because the recovery of glycinergic mIPSCs preceded GABAergic mIPSCs after transient inhibition of the vesicular $\mathrm{H}^{+}$-ATPase by bafilomycin (Katsurabayashi et al., 2004). Other factors may also regulate the relative content of glycine and GABA. For example, an association of VIAAT with GAD65 has been shown to provide a major kinetic advantage for the vesicular accumulation of newly synthesized GABA (Jin et al., 2003). Considering that synaptic vesicles contain up to 10 transporters (Takamori et al., 2006), their association or not with GAD65 is likely to alter the relative accumulation of glycine and GABA in vesicles (Katsurabayashi et al., 2004).

GlyT2 operation during vesicle refilling Because vesicles are recycled locally, neurotransmitter must also be supplied locally, and our results establish the capacity of GlyT2 to drive the filling of synaptic vesicles by uptake of glycine at low extracellular concentration (Fig. 11). This result extends genetic studies in knock-out GlyT2 mice and hyperekplexia patients (Gomeza et al., 2003; Rees et al., 2006) that established GlyT2 as a critical presynaptic determinant of glycinergic transmission. The punctuate expression of GlyT2 around presynaptic boutons (Zafra et al., 1995; Armsen et al., 2007) together with its $3 \mathrm{Na}^{+}$coupling and unidirectionality (Roux and Supplisson, 2000) combine to produce a local accumulation of glycine at the synapse.

GlyT2-mediated glycine uptake has been shown to be coupled to the transfer of 2.1 charges/glycine in recombinant system (Roux and Supplisson, 2000). Using this proportionality, the av-
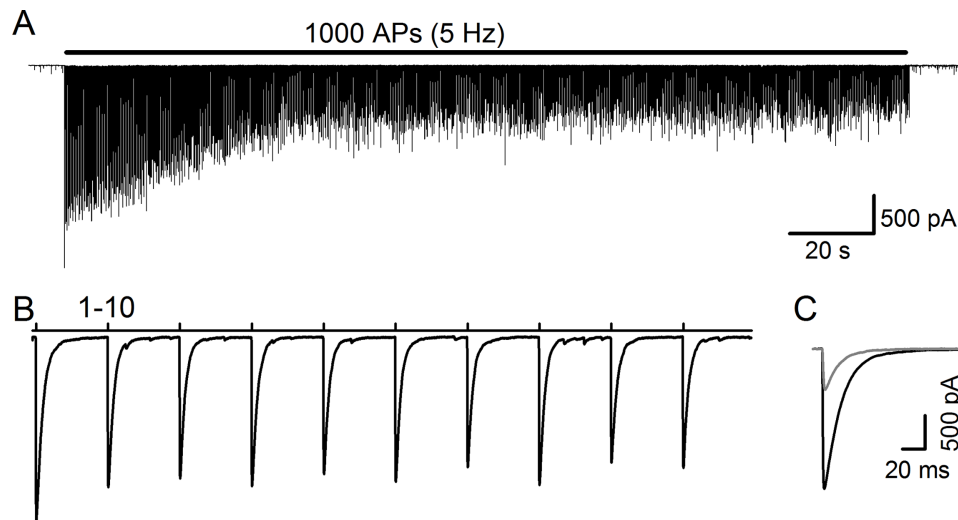

C
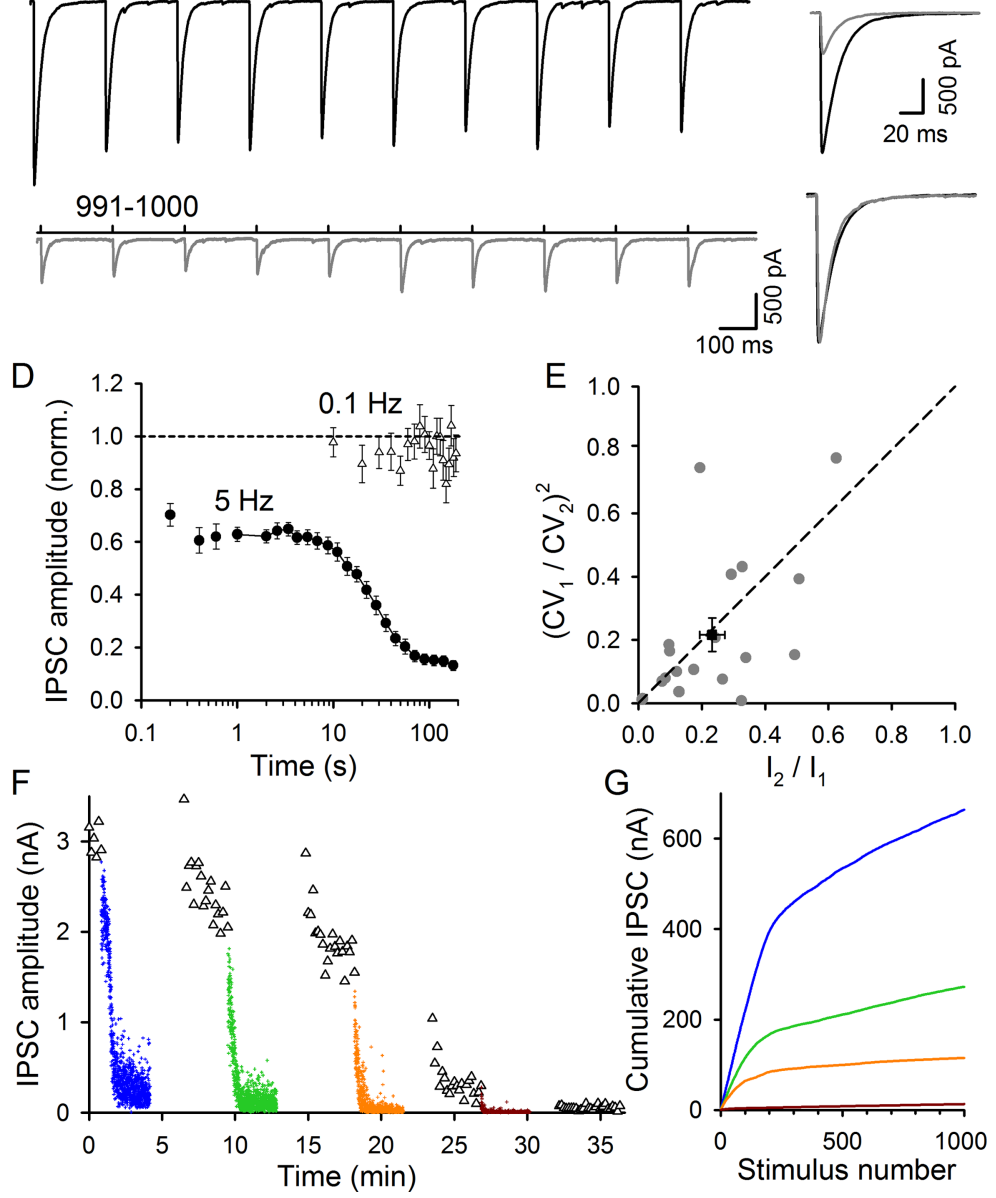

Figure 8. Different phases of glycine release during high-frequency stimulation. $A$, Trace of IPSCs evoked by 1000 APs triggered at $5 \mathrm{~Hz}$. B. Trace of IPSCs recorded at the onset (top traces; APs 1-10) and at the end (bottom traces; APs 991-1000) of $5 \mathrm{~Hz}$ stimulation. C, Averaged (top traces) and peaked scaled (bottom traces) IPSCs shown in Figure 7B. D, Time course of the absolute peak amplitude of IPSCs evoked by $5 \mathrm{~Hz}$ stimulation [IPSC were normalized to the first IPSC and averaged using a constant logarithmic bin (0.1); $n=18] . E$, Change in CV $^{2}$ plotted as a function of steady-state change in IPSC peak amplitude (see Materials and Methods). Individual pairs are represented with gray circles $(n=16)$, and the black square represents the mean \pm SEM. The dashed line represents a slope of 1 . $F$, Time course of the amplitude of IPCS recorded during four successive $5 \mathrm{~Hz}$ trains (crosses, depicted in different colors). After 2 min recovery, IPSCs were evoked at $0.1 \mathrm{~Hz}$ (triangles). G, Cumulative amplitude of IPSCS recorded in each $5 \mathrm{~Hz}$ trial (colors as in $\boldsymbol{F}$ ).

erage transporter current recorded in GlyT2 ${ }^{+}$neurons $(43 \mathrm{pA})$ (Fig. 1) is equivalent to a glycine influx of $208 \times 10^{-18} \mathrm{~mol} / \mathrm{s}$. Assuming that synaptic vesicles store 1790 molecules of neurotransmitters on average (Takamori et al., 2006), GlyT2-mediated uptake can supply enough glycine to refill $\sim 70000$ vesicles/s. This calculated filling rate suggests that, despite their low turnover/rates and their restriction to two-dimensional membranes, transporters can compete favorably with enzyme synthesis as a supply mechanism.

Transient uptake of glycine mediated by GlyT2 restored the amplitude of the evoked response after glycine depletion but not the tonic release during train of high-frequency stimulation. In 

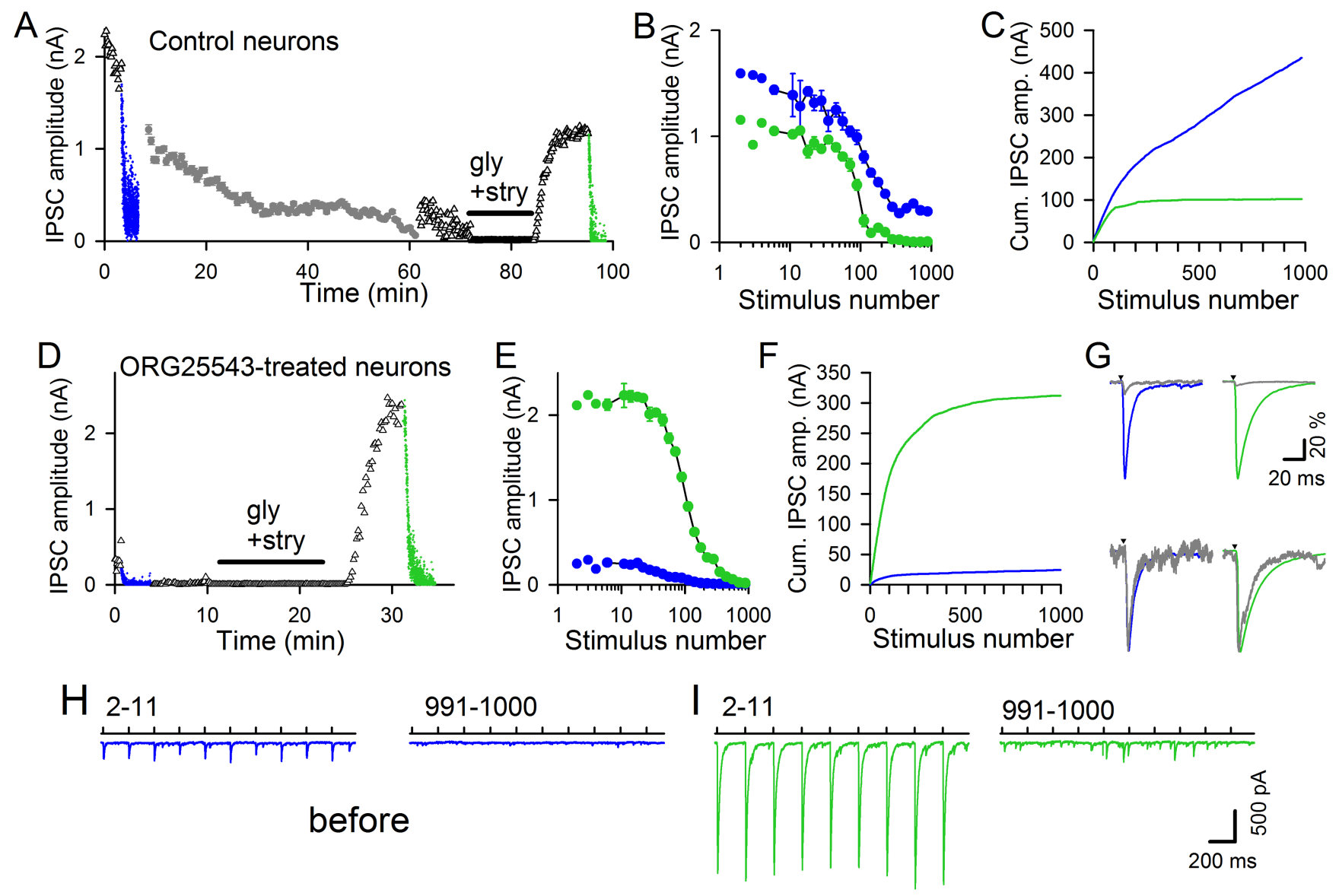

$991-1000$

\section{after gly}

Figure 9. GlyT2-mediated uptake rescued the initial but not the late phase of release during high-frequency stimulation. $\boldsymbol{A}$, Time course of the IPSC absolute amplitude evoked by continuous stimulation at different frequencies: $0.1 \mathrm{~Hz}$ (white triangles), $5 \mathrm{~Hz}$ (blue or green cross), and $1 \mathrm{~Hz}$ (gray circles represent the average amplitude per min). After a train of $1000 \mathrm{APs}$ evoked at $5 \mathrm{~Hz}$ (blue crosses), IPSCs were evoked at $1 \mathrm{~Hz}$ until a near complete dialysis of the presynaptic neuron was achieved. Then, glycine (100 $\mu \mathrm{m}$; solid bar) was applied for $10 \mathrm{~min}$ in the presence of strychnine (10 $\mu \mathrm{M}$; stry), and, after strychnine washout, a second $5 \mathrm{~Hz}$ train of $1000 \mathrm{APs}$ was triggered (green crosses). B, Peak amplitude of the IPSCs recorded during the two $5 \mathrm{~Hz}$ trains (colors as in A). C, Cumulative IPSC amplitude of the two 5 -Hz stimulations. D, Time course of the absolute IPSC peak amplitude recorded in an experiment similar to $A$ but using 0 RG25543-treated neurons. Note that the rundown was complete after the first $5 \mathrm{~Hz}$ train (blue crosses). $\boldsymbol{E}$, Peak amplitude of the IPSCs recorded during the tw0 5 -Hz trains (colors as in D). F, Cumulative IPSC amplitude before (blue line) and after (green line) glycine application. G, Raw (top traces) and normalized (bottom traces) average IPSCs recorded during the first (left) and the second (right) trains at the onset (blue or green lines) and at the end (gray line) of the $5 \mathrm{~Hz}$ stimulation. $\boldsymbol{H}, \boldsymbol{I}$, Traces of 10 consecutive IPSCs recorded at the onset (left) and end (right) of the first $(\boldsymbol{H})$ and second $(\boldsymbol{I}) 5 \mathrm{~Hz}$ stimulation. Solid line represents the time when the APs were triggered.

contrast, high concentrations of glycine in the pipette prevented the rundown induced by dialysis (Fig. 7C) and potentiated the amplitude of evoked IPSCs during tonic release (Fig. 10C). Together, these results suggest that short-term glycine uptake may not be sufficient to restore the high cytosolic concentration of glycine request for rapid vesicles refilling because of VIAAT low affinity.

In our experiments, we consistently found an increase in the decay time of miniature and evoked IPSCs after glycine application. Although we cannot exclude a postsynaptic change of GlyR properties attributable to the application of high concentrations of glycine and strychnine, presynaptic factors might be also involved in this effect. Indeed, it has been shown recently that corelease of GABA, a weak partial agonist of GlyRs, alters the deactivation kinetics of GlyRs and controls the fast decay of glycinergic IPSCs in auditory brainstem nucleus ( $\mathrm{Lu}$ et al., 2008). In our experiments, the proportion of GABA coreleased with glycine is likely to decrease after glycine application to dialyzed and ORG25543-treated neurons. According to Lu et al. (2008), lowering GABA corelease may alter the kinetics of glycinergic IPSCs in the direction reported here (Lu et al., 2008), from a fast decay in glycine-depleted cells to slower decay after glycine uptake.

In conclusion, our data provide new evidence supporting the role of GlyT2 for the recycling and refilling of synaptic vesicles in glycinergic neurons. This mechanism takes advantage of the peculiar properties of GlyT2 for generating and maintaining high glycine content in axon terminals. During evolution, these properties may have obviated the need for a dedicated mechanism of enzymatic synthesis of glycine in inhibitory neurons. Furthermore, membrane trafficking of GlyT2 may offer a simple mechanism to adjust precisely glycine supply in the presynaptic terminal.

\section{References}

Armsen W, Himmel B, Betz H, Eulenburg V (2007) The C-terminal PDZligand motif of the neuronal glycine transporter GlyT2 is required for efficient synaptic localization. Mol Cell Neurosci 36:369-380.

Asada H, Kawamura Y, Maruyama K, Kume H, Ding RG, Kanbara N, Kuzume H, Sanbo M, Yagi T, Obata K (1997) Cleft palate and decreased brain gamma-aminobutyric acid in mice lacking the $67-\mathrm{kDa}$ isoform of glutamic acid decarboxylase. Proc Natl Acad Sci U S A 94:6496-6499. 
Aubrey KR, Rossi FM, Ruivo R, Alboni S, Bellenchi GC, Le Goff A, Gasnier B, Supplisson S (2007) The transporters GlyT2 and VIAAT cooperate to determine the vesicular glycinergic phenotype. J Neurosci 27:6273-6281.

Awatramani GB, Turecek R, Trussell LO (2005) Staggered development of GABAergic and glycinergic transmission in the MNTB. J Neurophysiol 93:819-828.

Beato M, Burzomato V, Sivilotti LG (2007) The kinetics of inhibition of rat recombinant heteromeric alphalbeta glycine receptors by the low-affinity antagonist SR-95531. J Physiol 580:171-179.

Bedet C, Isambert MF, Henry JP, Gasnier B (2000) Constitutive phosphorylation of the vesicular inhibitory amino acid transporter in rat central nervous system. J Neurochem 75:1654-1663.

Blake JF, Cao CQ, Headley PM, Collingridge GL, Brugger F, Evans RH (1993) Antagonism of baclofen-induced depression of wholecell synaptic currents in spinal dorsal horn neurones by the potent GABAB antagonist CGP55845. Neuropharmacology 32: 1437-1440.

Bloomenthal AB, Goldwater E, Pritchett DB, Harrison NL (1994) Biphasic modulation of the strychnine-sensitive glycine receptor by $\mathrm{Zn}^{2+}$. Mol Pharmacol 46:1156-1159.

Bradaïa A, Schlichter R, Trouslard J (2004) Role of glial and neuronal glycine transporters in the control of glycinergic and glutamatergic synaptic transmission in lamina $\mathrm{X}$ of the rat spinal cord. J Physiol 559:169-186.

Brewer GJ, Torricelli JR, Evege EK, Price PJ (1993) Optimized survival of hippocampal neurons in B27-supplemented Neurobasal, a new serum-free medium combination. J Neurosci Res 35:567-576.

Burger PM, Hell J, Mehl E, Krasel C, Lottspeich F, Jahn R (1991) GABA and glycine in synaptic vesicles: storage and transport characteristics. Neuron 7:287-293.

Caulfield WL, Collie IT, Dickins RS, Epemolu O, McGuire R, Hill DR, McVey G, Morphy JR, Rankovic Z, Sundaram H (2001) The first potent and selective inhibitors of the glycine transporter type 2. J Med Chem 44:2679-2682.

Chéry N, de Koninck Y (1999) Junctional versus extrajunctional glycine and $\mathrm{GABA}_{\mathrm{A}}$ receptormediated IPSCs in identified lamina I neurons of the adult rat spinal cord. J Neurosci 19:7342-7355.

Clements JD (1996) Transmitter timecourse in the synaptic cleft: its role in central synaptic function. Trends Neurosci 19:163-171.

Daly E (1990) The biochemistry of glycinergic neurons. In: Glycine neurotransmission (Ottersen O, Storm-Mathisen J, eds), pp 25-66. Chichester, UK: Wiley.

Dugué GP, Dumoulin A, Triller A, Dieudonné S (2005) Target-dependent use of coreleased inhibitory transmitters at central synapses. J Neurosci 25:6490-6498.

Edwards RH (2007) The neurotransmitter cycle and quantal size. Neuron 55:835-858.

Engel D, Pahner I, Schulze K, Frahm C, Jarry H, Ahnert-Hilger G, Draguhn A (2001) Plasticity of rat central inhibitory synapses through GABA metabolism. J Physiol 535:473-482.

Faber DS, Korn H (1991) Applicability of the coefficient of variation method for analyzing synaptic plasticity. Biophys J 60:1288-1294.

Foster KA, Regehr WG (2004) Variance-mean analysis in the presence of a rapid antagonist indicates vesicle depletion underlies depression at the climbing fiber synapse. Neuron 43:119-131.

Friauf E, Aragón C, Löhrke S, Westenfelder B, Zafra F (1999) Developmen- tal expression of the glycine transporter GLYT2 in the auditory system of rats suggests involvement in synapse maturation. J Comp Neurol 412:17-37.

Gaffield MA, Betz WJ (2006) Imaging synaptic vesicle exocytosis and endocytosis with FM dyes. Nat Protoc 1:2916-2921.

Gao BX, Stricker C, Ziskind-Conhaim L (2001) Transition from GABAergic to glycinergic synaptic transmission in newly formed spinal networks. J Neurophysiol 86:492-502.

Geiman EJ, Zheng W, Fritschy JM, Alvarez FJ (2002) Glycine and GABA(A) receptor subunits on Renshaw cells: relationship with presynaptic neurotransmitters and postsynaptic gephyrin clusters. J Comp Neurol 444:275-289.

Gomeza J, Ohno K, Hülsmann S, Armsen W, Eulenburg V, Richter DW, Laube B, Betz H (2003) Deletion of the mouse glycine transporter 2 results in a hyperekplexia phenotype and postnatal lethality. Neuron 40:797-806.

Hanus C, Vannier C, Triller A (2004) Intracellular association of glycine receptor with gephyrin increases its plasma membrane accumulation rate. J Neurosci 24:1119-1128.

Hirzel K, Müller U, Latal AT, Hülsmann S, Grudzinska J, Seeliger MW, Betz H, Laube B (2006) Hyperekplexia phenotype of glycine receptor alpha1 
A

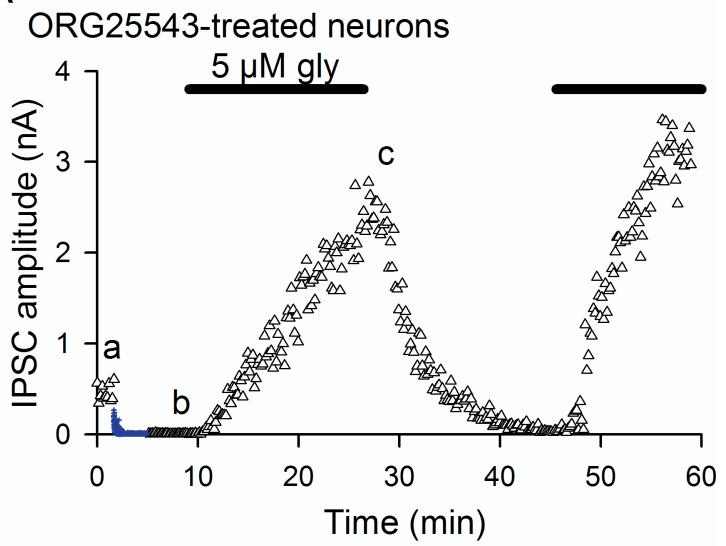

B
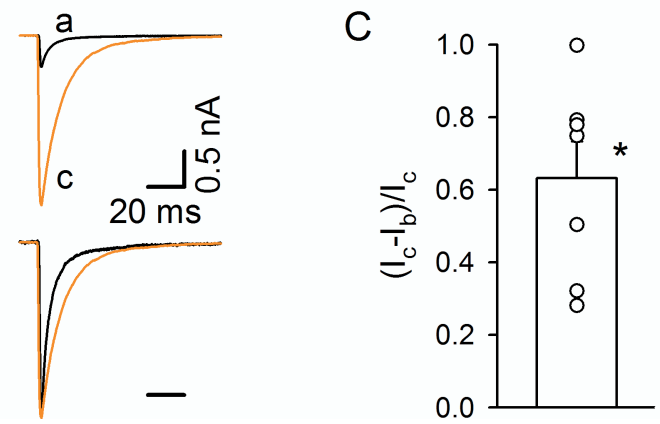

Figure 11. Direct coupling between GlyT2-mediated uptake and vesicle refilling. $\boldsymbol{A}$, Time course of glycinergic IPSC amplitude during continuous stimulation at $0.1 \mathrm{~Hz}$ (white triangles) in the absence or presence of $5 \mu \mathrm{m}$ extracellular glycine (solid bar) in an 0RG25543-treated neuron. As in Figure $9 D$, an initial $5 \mathrm{~Hz}$ stimulation train (1000 APs) was sufficient to induce a complete rundown of the response (blue crosses). $\boldsymbol{B}$, Raw (top traces) and normalized (bottom traces) average IPSCs recorded at the beginning of the trace (a; solid line) and after glycine application (c; orange line). C, Relative change in IPSC amplitude during glycine application in ORG25543-treated pairs $(n=7 ; p<0.05) . \mathrm{I}_{\mathrm{b}}$ and $\mathrm{I}_{\mathrm{c}^{\prime}}$ Average amplitude of $10 \mathrm{IPSC}$ before $\left(\mathrm{I}_{\mathrm{b}}\right)$ and at the end $\left(I_{c}\right)$ of $5 \mu \mathrm{m}$ glycine application, as indicated in Figure $11 \mathrm{~A}$.

subunit mutant mice identifies $\mathrm{Zn}(2+)$ as an essential endogenous modulator of glycinergic neurotransmission. Neuron 52:679-690.

Hossaini M, French PJ, Holstege JC (2007) Distribution of glycinergic neuronal somata in the rat spinal cord. Brain Res 1142:61-69.

Jin H, Wu H, Osterhaus G, Wei J, Davis K, Sha D, Floor E, Hsu CC, Kopke RD, Wu JY (2003) Demonstration of functional coupling between gammaaminobutyric acid (GABA) synthesis and vesicular GABA transport into synaptic vesicles. Proc Natl Acad Sci USA 100:4293-4298.

Jonas P, Bischofberger J, Sandkühler J (1998) Corelease of two fast neurotransmitters at a central synapse. Science 281:419-424.

Jones MV, Westbrook GL (1995) Desensitized states prolong GABAA channel responses to brief agonist pulses. Neuron 15:181-191.

Jüngling K, Eulenburg V, Moore R, Kemler R, Lessmann V, Gottmann K (2006) $\mathrm{N}$-cadherin transsynaptically regulates short-term plasticity at glutamatergic synapses in embryonic stem cell-derived neurons. J Neurosci 26:6968-6978.

Jursky F, Nelson N (1995) Localization of glycine neurotransmitter transporter (GLYT2) reveals correlation with the distribution of glycine receptor. J Neurochem 64:1026-1033.

Katsurabayashi S, Kubota H, Higashi H, Akaike N, Ito Y (2004) Distinct profiles of refilling of inhibitory neurotransmitters into presynaptic terminals projecting to spinal neurones in immature rats. J Physiol 560:469-478

Kay AR, Alfonso A, Alford S, Cline HT, Holgado AM, Sakmann B, Snitsarev VA, Stricker TP, Takahashi M, Wu LG (1999) Imaging synaptic activity in intact brain and slices with FM1-43 in C. elegans, lamprey, and rat. Neuron 24:809-817.

Keller AF, Coull JA, Chery N, Poisbeau P, De Koninck Y (2001) Regionspecific developmental specialization of GABA-glycine cosynapses in laminas I-II of the rat spinal dorsal horn. J Neurosci 21:7871-7880.
Kotak VC, Korada S, Schwartz IR, Sanes DH (1998) A developmental shift from GABAergic to glycinergic transmission in the central auditory system. J Neurosci 18:4646-4655.

Laube B (2002) Potentiation of inhibitory glycinergic neurotransmission by $\mathrm{Zn}^{2+}$ : a synergistic interplay between presynaptic P2X2 and postsynaptic glycine receptors. Eur J Neurosci 16:1025-1036.

Laube B, Kuhse J, Rundstrom N, Kirsch J, Schmieden V, Betz H (1995) Modulation by zinc ions of native rat and recombinant human inhibitory glycine receptors. J Physiol 483:613-619.

Laube B, Kuhse J, Betz H (2000) Kinetic and mutational analysis of $\mathrm{Zn}^{2+}$ modulation of recombinant human inhibitory glycine receptors. J Physiol 522:215-230.

Lim R, Alvarez FJ, Walmsley B (2000) GABA mediates presynaptic inhibition at glycinergic synapses in a rat auditory brainstem nucleus. J Physiol 525:447-459.

Liu G (2003) Presynaptic control of quantal size: kinetic mechanisms and implications for synaptic transmission and plasticity. Curr Opin Neurobiol 13:324-331.

Liu QR, López-Corcuera B, Mandiyan S, Nelson H, Nelson N (1993) Cloning and expression of a spinal cord- and brain-specific glycine transporter with novel structural features. J Biol Chem 268:22802-22808.

Lu T, Rubio ME, Trussell LO (2008) Glycinergic transmission shaped by the corelease of GABA in a mammalian auditory synapse. Neuron 57:524-535.

Lynch JW (2004) Molecular structure and function of the glycine receptor chloride channel. Physiol Rev 84:1051-1095.

Mackie M, Hughes DI, Maxwell DJ, Tillakaratne NJ, Todd AJ (2003) Distribution and colocalisation of glutamate decarboxylase isoforms in the rat spinal cord. Neuroscience 119:461-472.

Mathews GC, Diamond JS (2003) Neuronal glutamate uptake contributes to GABA synthesis and inhibitory synaptic strength. J Neurosci 23:2040-2048.

Mathias RT, Cohen IS, Oliva C (1990) Limitations of the whole cell patch clamp technique in the control of intracellular concentrations. Biophys J 58:759-770.

McIntire SL, Reimer RJ, Schuske K, Edwards RH, Jorgensen EM (1997) Identification and characterization of the vesicular GABA transporter. Nature 389:870-876.

Miller PS, Da Silva HM, Smart TG (2005) Molecular basis for zinc potentiation at strychnine-sensitive glycine receptors. J Biol Chem 280:37877-37884.

Nabekura J, Katsurabayashi S, Kakazu Y, Shibata S, Matsubara A, Jinno S, Mizoguchi Y, Sasaki A, Ishibashi H (2004) Developmental switch from GABA to glycine release in single central synaptic terminals. Nat Neurosci 7:17-23.

O'Brien JA, Berger AJ (1999) Cotransmission of GABA and glycine to brain stem motoneurons. J Neurophysiol 82:1638-1641.

Ottersen OP, Storm-Mathisen J, Laake JH (1990) Cellular and subcellular localization of glycine studied by quantitative electron microscopic immunocytochemistry. In: Glycine neurotransmission (Ottersen OP, Storm-Mathisen J, eds), pp 303-328. Chichester, UK: Wiley.

Rees MI, Harvey K, Pearce BR, Chung SK, Duguid IC, Thomas P, Beatty S, Graham GE, Armstrong L, Shiang R, Abbott KJ, Zuberi SM, Stephenson JB, Owen MJ, Tijssen MA, van den Maagdenberg AM, Smart TG, Supplisson S, Harvey RJ (2006) Mutations in the gene encoding GlyT2 (SLC6A5) define a presynaptic component of human startle disease. Nat Genet 38:801-806.

Rigo JM, Legendre P (2006) Frequency-dependent modulation of glycine receptor activation recorded from the zebrafish larvae hindbrain. Neuroscience 140:389-402.

Rigo JM, Badiu CI, Legendre P (2003) Heterogeneity of postsynaptic receptor occupancy fluctuations among glycinergic inhibitory synapses in the zebrafish hindbrain. J Physiol 553:819-832.

Roux MJ, Supplisson S (2000) Neuronal and glial glycine transporters have different stoichiometries. Neuron 25:373-383.

Russier M, Kopysova IL, Ankri N, Ferrand N, Debanne D (2002) GABA and glycine co-release optimizes functional inhibition in rat brainstem motoneurons in vitro. J Physiol 541:123-137.

Sagné C, El Mestikawy S, Isambert MF, Hamon M, Henry JP, Giros B, Gasnier B (1997) Cloning of a functional vesicular GABA and glycine transporter by screening of genome databases. FEBS Lett 417:177-183.

Shiang R, Ryan SG, Zhu YZ, Hahn AF, O’Connell P, Wasmuth JJ (1993) 
Mutations in the alpha 1 subunit of the inhibitory glycine receptor cause the dominant neurologic disorder, hyperekplexia. Nat Genet 5:351-358.

Sulzer D, Pothos EN (2000) Regulation of quantal size by presynaptic mechanisms. Rev Neurosci 11:159-212.

Suwa H, Saint-Amant L, Triller A, Drapeau P, Legendre P (2001) Highaffinity zinc potentiation of inhibitory postsynaptic glycinergic currents in the zebrafish hindbrain. J Neurophysiol 85:912-925.

Takamori S, Holt M, Stenius K, Lemke EA, Grønborg M, Riedel D, Urlaub H, Schenck S, Brügger B, Ringler P, Müller SA, Rammner B, Gräter F, Hub JS, De Groot BL, Mieskes G, Moriyama Y, Klingauf J, Grubmüller H, Heuser J, Wieland F, Jahn R (2006) Molecular anatomy of a trafficking organelle. Cell 127:831-846.

Tanaka I, Ezure K (2004) Overall distribution of GLYT2 mRNA-containing versus GAD67 mRNA-containing neurons and colocalization of both mRNAs in midbrain, pons, and cerebellum in rats. Neurosci Res 49:165-178.

Todd AJ, Watt C, Spike RC, Sieghart W (1996) Colocalization of GABA, glycine, and their receptors at synapses in the rat spinal cord. J Neurosci 16:974-982.

Wang P, Slaughter MM (2005) Effects of GABA receptor antagonists on retinal glycine receptors and on homomeric glycine receptor alpha subunits. J Neurophysiol 93:3120-3126.

Wojcik SM, Katsurabayashi S, Guillemin I, Friauf E, Rosenmund C, Brose N, Rhee JS (2006) A shared vesicular carrier allows synaptic corelease of GABA and glycine. Neuron 50:575-587.

Xu-Friedman MA, Regehr WG (2004) Structural contributions to shortterm synaptic plasticity. Physiol Rev 84:69-85.

Zafra F, Aragón C, Olivares L, Danbolt NC, Giménez C, Storm-Mathisen J (1995) Glycine transporters are differentially expressed among CNS cells. J Neurosci 15:3952-3969.

Zeilhofer HU, Studler B, Arabadzisz D, Schweizer C, Ahmadi S, Layh B, Bösl MR, Fritschy JM (2005) Glycinergic neurons expressing enhanced green fluorescent protein in bacterial artificial chromosome transgenic mice. J Comp Neurol 482:123-141. 